\title{
Influences of Environmental Humidity on Physical Properties and Attrition of Wood Pellets
}

\author{
Tong Deng ${ }^{1, *}$, Abdullah M. Alzahrani ${ }^{2}$ and Michael S Bradley ${ }^{1}$ \\ ${ }^{1}$ The Wolfson Centre for Bulk Solids Handling Technology, Faculty of Engineering \& Science, \\ University of Greenwich, Central Avenue, Chatham, Kent ME4 4TB, UK \\ ${ }^{12}$ King Saud Medical City, Riyadh, Kingdom of Saudi Arabia \\ * Corresponding author: Tel.: ++44 (0)20 8331 9951; Email: t.deng@greenwich.ac.uk
}

\begin{abstract}
Wood pellets have been widely used for power generation and domestic heating recently to substitute fossil fuels. For health and safety reasons, particle degradation and dusts generation in material storage and handling processes are always a serious concern for anyone involved. Also the level of fines in wood pellets can strongly influence fuel milling and combustion. For previous study, wood pellets attrition subjected to its mechanical properties has been reported. However pellet mechanical properties can be inconsistent and influenced by environmental conditions such as humidity, temperature and storage time.
\end{abstract}

In this paper, attrition behaviour and dust generation of two types of wood pellets have been studied, which the pellets were stored in a constant relative humidity environment for a period of time (4 days). Physical properties such as moisture contents, bulk density and flexural stress of the pellets were measured for the pellets conditioned in a RH chamber, which was believed that equilibrium condition was achieved. Correspondingly, the conditioned pellets for a number of different humidity levels were tested for both impact test and dustiness test. The study shows that the pellets can lose structural strength due to in taking moisture from environment for a high relative humidity. Also a high humidity can result in an increased level of pellet degradation and dusts generated.

Keywords: Wood Pellets, Attrition, Dusts, Humidity influence, Physical properties;

\section{Introduction}

With attention to a 'green' fuel source to reduce carbon emission, wood pellets have been widely used for two primary sectors: industrial sector (substitute for coal in power plants), and residential sector (for domestic heating). Global usage of wood pellets for both sectors, have had significant growth in the past decade, which reached about 26 million metric tonnes in 2015 [1] and continues to grow.

Compared to other biomass fuels, wood pellets can offer many advantages such as high bulk density, high stability and low moisture contents. In terms of transport costs, wood pellets have less volume to handle, and also facilitate less storage and transportation due to its high energy content than wood chips, logs or other raw biomass. A low moisture content and uniform particle shape also provides better handling ability in storage and transport [2]. However wood pellets still suffer from a number of problems in storage and handling process. Pellet attrition is one major problem, which may produce dust and influence milling and combustion performance [3]. Dust generated in handling and transportation can result in serious health and safety issues in the working environment [4], which requires evaluation and control of the dust and fine contents and their migration in the handling process. Wood pellets flow through multiple handling stages from manufacturers (often overseas) to reach final users, e.g., power stations [5]. Evaluation and control of fines (small part of broken pellets) and dusts (often thought of as those debris so fine they can suspend in air) in the multiple handling stages can be difficult, while the pellets physical properties can be changed through storage and transport in different environments.

To access attrition of wood pellets, a number of evaluation methods including mechanical properties and dust generation have been developed and used in industry such as durability test [6-9]. However 
these assessments normally evaluate the pellets attrition with constant physical properties for the time when the wood pellets are taken without considering further storage time. In reality, wood pellets are quite often kept in storage for a relatively long period before being moved to the next stage, or sit in transport vehicles (e.g. ship holds) for long distance travel. Storage conditions such as humidity must change from time to time. Some previous research already noted that mechanical properties of wood pellets would change due to exposure to high humidity in stockpiles or severe environmental condition changes $[10,11]$. These changes consequently influence the durability of the pellet fuels and the level of fines and dust generated. Varied wood pellet attrition leads to a difficult situation where the material being handled can be from quite clean to extremely high fine (level can be $0 \%$ to $40 \%$ [12]) so the handling characteristics including flowability, dustiness, density and grinding ability may change from hour to hour in the plant, although it also depends upon silo operational status [13]. Consequently, it becomes very hard to optimize the systems for reliable, energy efficient operation and safety control [2]. Therefore it is necessary to investigate the influence of environmental humidity on physical properties and attrition of wood pellets to provide a better understanding of the need for humidity control in storage and transport.

In this paper, the influence of humidity on physical properties and attrition of wood pellets has been studied include moisture absorption, moisture contents, bulk density and mechanical strength, which can be critical to pellet attrition and dust generation [14]. The pellet attrition has been evaluated using a rotary impact attrition tester for pellet samples conditioned at different relative humidity (RH) levels.

\section{Physical properties of wood pellets}

Wood pellets are made of woodchips or sawdust in uniform shapes normally 6 - $8 \mathrm{~mm}$ in diameter and $3-40 \mathrm{~mm}$ in length [15]. It gives a bulk density of typically over $600 \mathrm{~kg} / \mathrm{m}^{3}$. In the pelletizing process, the wood chips or sawdust is compacted into a uniform cylindrical shape with a polished appearance on the outsides of the pellets, which can prevent absorbing moisture from the ambient environment [16]. Appearance of wood pellets is shown in Figure 1, which are the samples used for current study.

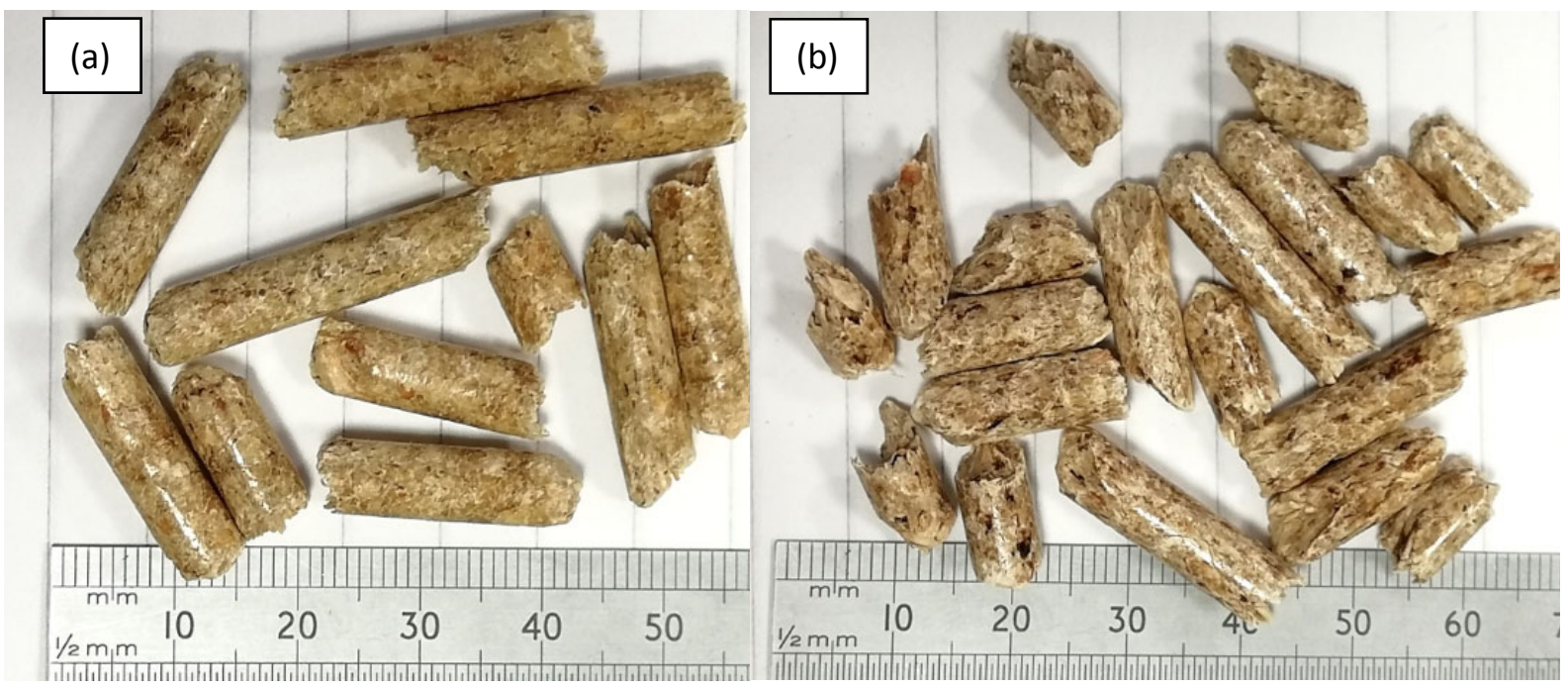

Figure 1: The wood pellets being tested, (a) Pine wood pellets, (b) Recycled wood pellets

For fuel purposes, physical properties typically of interest with wood pellets are physical dimensions, i.e., pellet lengths, bulk density rather than solid density, moisture contents, pellet strength or mechanical durability, etc. Other important specifications may include net calorific value, elemental contents such as nitrogen, sulphur and chlorine, and ash contents, etc. [17]. However, these combustion-related properties are not important to the pellet attritions. 


\subsection{Pellet dimensions}

As mentioned above, wood pellets are made to a uniform diameter of $6 \mathrm{~mm}$ or $8 \mathrm{~mm}$ with varied lengths of $3-40 \mathrm{~mm}$ in standards $[15,16]$. Because of pelletizing process, pellet length becomes a critical term for evaluating the quality of wood pellets. In EnPlus A-1 standard [18], fine particles are defined as the particle length is smaller than $3.15 \mathrm{~mm}$, but the size of dust for wood pellets has not been defined in the standards.

The meaning of the term "dust" is not universally agreed. With standard durability tests of wood pellets, the dust is particles picked up by an air flow of $175 \mathrm{l} / \mathrm{min}$ [19], which gives a maximum size of dust up to $1.0 \mathrm{~mm}$ [9]. With the British standard [6], a smaller air flow rate is used, $38 \mathrm{l} / \mathrm{min}$. In this case, it is likely that the dust size of D90 is less than $300 \mu \mathrm{m}$. As there is no standard dust size so far for wood pellets, it is sensible to define the dust size for wood pellets as less than $850 \mu \mathrm{m}$, which can be easily picked up by an air flow. Therefore the pellet dimensions can be: normal standard wood pellets are $3.15 \mathrm{~mm}-40 \mathrm{~mm}$; fines in wood pellets are $0.85 \mathrm{~mm}-3.15 \mathrm{~mm}$; and dusts in wood pellets are $\leq 0.85 \mathrm{~mm}$.

To assess wood pellet attrition, two categories need to be studied; fines and dust, by different methods, because the mechanisms of pellets attrition are different and may have significantly different influences on pellet attritions with changes in pellet quality. A previous study has reported the influence of pellet dimensions on pellet durability and attrition, which concluded that longer pellets seem more durable with a higher pellet strength [20]. Hence, the pellet dimension can be an important parameter in assessing the quality of wood pellets for attrition of the pellets [14].

\subsection{Bulk density}

Bulk density is an important parameter for wood pellets, which directly influences storage and transportation costs [21]. It is defined as weight of bulk pellets in a unit of volume, which can be influenced by a number of factors, including fine contents. Another influence factor is moisture content of the pellets. It is often seen that for clean pellets the bulk density is just over $600 \mathrm{~kg} / \mathrm{m}^{3}$. Previous research shows the shorter pellets have a higher moisture content and are less durable [22], which often have a lower bulk density. It has been found that an increased bulk density of the pellets is normally due to a reduced moisture content but also due to increased fines content in pellets [23].

\subsection{Moisture content}

Moisture content, usually expressed on a "wet basis" as defined in Eq. 1, has a great impact on bulk density of wood pellets [24]. The moisture in wood pellets is originally from a number of sources. To make the pellets, the raw materials must contain a certain level of moisture [15], which is typically about $7 \%-10 \%[14]$.

$$
\text { Moisture content }(\%)=\frac{\text { Mass of water in a unit weight of sample }(g)}{\text { mass of the unit weight pellet sample before drying }(g)} \times 100
$$

Whittaker [14] gave a detailed discussion of moisture content influence on wood pellet durability. As a summary, for different types of wood pellets previous researches showed completed opposed correlations between moisture content and pellet durability; some research suggested a positive correlation roughly between $7 \%-15 \%$ moisture contents for scots pine [24], tulip wood [25], and some hardwoods [26]. However a number of studies reported a negative correlation between moisture contents and pellet durability for $5 \%-14 \%$ moisture in beech [27], and olive pruning residues [28]. A later study showed that there could be an optimum moisture content for pellet durability in sawdust produced pellets at different storage time [23] and the phenomenon was also mentioned by Whittaker [14] and a number of other researchers [29]. Consequently the moisture content of pellets may have 
a link with pellet attrition and size reduction. Graham's study showed that a long storage time with high humidity formed cracks and disintegration of the pellets due to reduced pellet strength [10]. Also, Kaliyan [29] concluded that strength and durability of the wood pellets increased with increasing moisture content until an optimum value was reached, although Kaliyan's conclusion was for making the pellets.

\subsection{Pellet strength and durability}

The term "wood pellet strength" is less common than "durability" of pellets, which may refer to both the compressive and impact resistance of a pellet. Compressive resistance testing simulates the loading due to self-weight in storage and the crushing of pellets in (for example) a screw conveyor. Impact resistance testing simulates the impact forces induced on pellets during handling in the filling of silos, bins or storage bays when pellets are dropped either on a hard floor or onto one another [30]. Pellet strength is sometimes useful when considering bulk delivery systems, and may be assessed by tensile strength or flexural stress [11].

Durability or abrasive resistance is in general defined as the ability to withstand wear and tear, decay, and loss of material through continual use; resistance to change from original appearance; or the ability to resist weathering action or chemical attack [31]. Mechanical durability also means abrasion strength and mechanical strength as compressive and impact resistance [29]. The different tests commonly used measure different aspects of these losses.

Although the tests may be different, durability of wood pellets is usually described by:

$$
\text { Durability }(\%)=\frac{\text { Mass of the oversized sample after test }(g)}{\text { Original mass of the test sample }(g)} \times 100
$$

In the standards, the oversize is defined as retained on a $3.15 \mathrm{~mm}$ round-hole sieve [6] and this is consistent amongst most standards and users for durability tests. But as Frew [9] pointed out, for dustiness tests of wood pellets the oversize may have different meanings according to different standards.

\section{Wood pellets attrition}

As Thomas indicated [32], when forces were involved that were static or dynamic as a consequence of movement, handling of wood pellets caused attrition that caused small pieces to be broken down from the whole pellets. It is widely recognised that there are essentially two different attrition mechanisms: fragmentation and abrasion shown in Figure 2 [32].
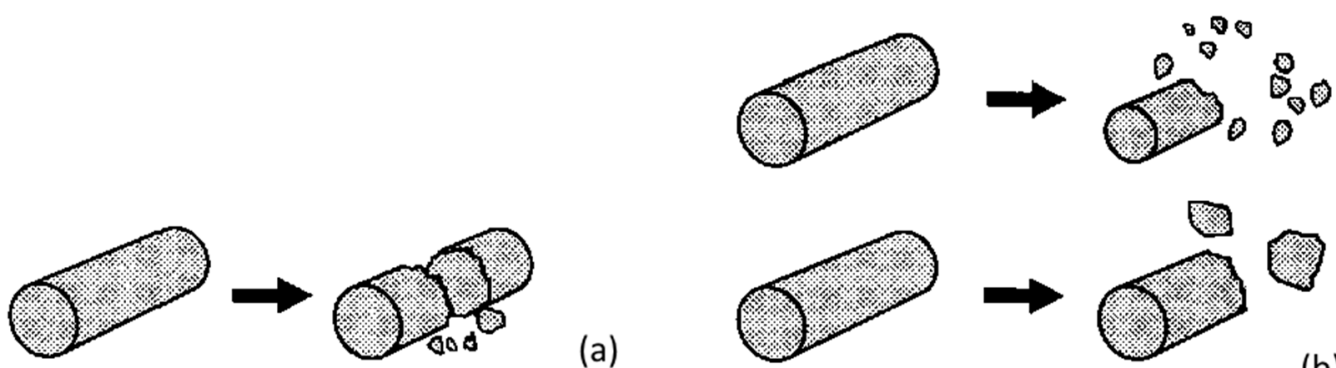

(a)
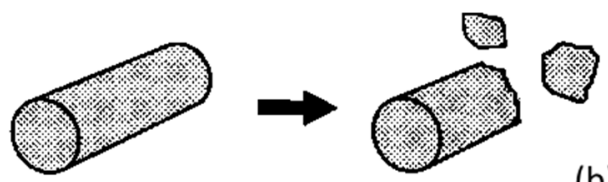

(b)

Figure 2: Two types of wood pellet attritions: (a) Fragmentation; (b) Abrasion [32]

\subsection{Fragmentation and impact attrition}

With fragmentation of wood pellets, because of their special shape (cylindrical shape with varied length), the pellets may break in the middle due to impact force acting on one end of the pellet and 
bending the pellet or causing large cracks. It causes large chunks to fall off from the original pellets and the pellets to break down into smaller size, each of which would be significantly bigger than the nominated dust size. The fragmentation of wood pellets could happen when dropping the pellets at a transfer point, in a pneumatic conveyor or loading pellets into a big silo. Not only dynamic impacts cause pellet fragments, but also does uneven loading stress acting on the pellets in storage.

Generally, wood pellets with dynamic impacts have a high chance to break into big pieces due to strong impact force. Pellet fragmentation increases the number of smaller pellets significantly, but relatively less dust is generated compared to abrasion attrition. The cracks can be in any direction, but are more likely through radial direction as a result of small cross-section area compared to pellet length. Therefore pellet fragmentation will depend on pellet strength, impact conditions such as velocity and angle, hardness of the surface collided with and maybe moisture contents.

\subsection{Abrasive attrition}

Abrasion of wood pellets is defined as fracture on the edges or surface-unevenness of the pellets [32]. Due to manufacture methods of wood pellets, the pellets form a uniform cylindrical shape with varied length from small wood chips by binding process. Pellet strength depends on solid-solid bonds between ingredient particles or the use of specific pellet binders. It may also depend on interactions between the small particles due to particle folding and plying. Therefore pellet strength may not be uniform through each whole individual pellet. The bonding between some of the individual small particles at the surface of a pellet may be relatively weak compared to the whole pellet and these are easy to break off even with gentle rubbing actions such as movement in discharge from storage. So abrasive attrition tends to produce mainly small fines (dust) compared to fragmentation attrition which produces a wider range of particle sizes.

\subsection{Evaluation methods}

Many evaluation methods for attrition and dust generation of wood pellets have been developed previously such as durability test [6-9]. Durability of wood pellets is defined in Eq. 2, by determining a ratio between the mass of oversized sample after durability tests and the original sample mass. In published standards, the oversize is defined as $3.15 \mathrm{~mm}$ [6] for mechanical durability, however for dustiness tests the oversize of wood pellets is different according to different standards which depends on test method [9].

Tumbling method [33] has been widely used to estimate pellet quality in terms of dust number [9] or durability defined in Eq. 2 . The test simulates mechanical movement of pellets in handling process and measures fines produced due to the process. During the tumbling, the pellets gently impact and shear over each other or against the wall of the container. According to different standards, dust number can be slightly different because suction air flow rate is different (AS standard is $175 \mathrm{l} / \mathrm{min}$ [19] and EN standard is $38 \mathrm{I} / \mathrm{min}$ [9]). For the tumbling method, it proposes to measure fugitive dust emissions from the processing, storage, handling and loading/offloading of bulk materials such as wood pellets. However it appears not very effective as an indicator of pellet attrition under dynamic impacts when travelling at a velocity (such as in transfer points and pneumatic conveyor bends), because relative movement of pellets in the tumbler is too small, velocity is very low and the main action is abrasion. A recent study [34] concluded that the forces acting on particles in the tumbling box underestimated the realistic handling conditions assumed such as filling from large heights (up to $21 \mathrm{~m}$ ) and reclaiming at the bottom of a silo.

Other than the tumbling method, Oveisi-Fordiie [31] reviewed a number test methods for wood pellet durability. One is the Ligno tester where pellets are exposed to shocks caused by air stream which induces the particles to collide with each other and the wall of equipment. The small sample of 100 
grams and lack of air stream control cause a higher variability between experiments and affect the repeatability of the durability measurement. Another one is the Holmen tester where pellets are introduced in a stream of air and pneumatically conveyed in a closed pipeline to simulate a more vigorous treatment of pellets. After treatment, the samples are sieved again with a sieve having an opening of about $80 \%$ of the pellet diameter. Similarly the Holmen tester is very restricted to air supply and has similar problems. Another important drawback with the Holmen test is that the acceleration length between impacts is far too short to simulate the effects in a real pneumatic conveying system. The last one mentioned by Oveisi-Fordiie [31] is the drop test, where a five-meter drop tower is used to facilitate dropping the samples onto different test surfaces. Due to the controlled drop heights, drop velocity of pellets is well controlled and the amount of dust generated in handling situation is closer to reality. However the drop velocity is limited by the heights and is not sufficient to simulate the high velocity in pneumatic conveying systems which are very widely used for pellet delivery.

Recently a rotary impact tester has been developed for assessing breakage of large particles (>1.0 mm) under dynamic impacts with a controlled velocity against hard metal surfaces at the Wolfson Centre $[12,35]$. Advantages of the rotary impact tester to determine particle attrition for impact attrition are the well-controlled impact conditions such as particle velocity (by adjusting spinning speed of the disc) and impact angles against targets (setting target angles), which are the key factors for estimating degradation level of pellet fragmentation under impacts. However the rotary impact tester may overestimate pellet attrition compared to that in real pneumatic conveying systems.

\section{Experimental study}

\subsection{Test materials}

Two types of sample materials were used; pine wood pellets and recycled wood pellets as shown in Figure 1. The pine wood pellets were made by Forever Fuels to meet high quality standard (ENplus A1). They were produced from virgin wood fibres and stored in a natural environment (water-tight but unheated shed) for about two years before testing. Average moisture of the pine wood pellets was about 5.1\% w.b. (wet basis). The recycled pellets were manufactured in the UK (Woody Wood Products) to the ENplus standard, approved by the Forest Stewardship Council (FSC). The recycled pellets were made from $100 \%$ waste wood and were specified as $8-10 \%$ moisture indicated by the supplier, but was about 5.5\% w.b. measured from the received samples. All the pellets are cylindrical of $6 \mathrm{~mm}$ in diameter and about $15-40 \mathrm{~mm}$ long. Typical sizes of the pellets tested are summarised in Table 1.

Table 1: Size distributions of virgin pellets before the tests (percentage in weight)

\begin{tabular}{|c|c|c|}
\hline Length (mm) & Pine wood pellets & Recycled wood pellets \\
\hline$<\mathbf{1 0}$ & $3 \%$ & $15 \%$ \\
\hline $\mathbf{1 0}-\mathbf{2 0}$ & $57 \%$ & $38 \%$ \\
\hline $\mathbf{2 0}-\mathbf{3 0}$ & $30 \%$ & $45 \%$ \\
\hline$>\mathbf{3 0}$ & $10 \%$ & $2 \%$ \\
\hline
\end{tabular}

\subsection{Experimental procedures and rigs}

\subsubsection{Physical properties of the samples}

In the tests, a number of physical properties of the pellets have been monitored, such as moisture contents, bulk density and pellet strength.

Moisture contents of pellets defined in Eq.1 were determined by using a moisture analyser (Moisture Analyzer MB35, Ohaus, US), in which 10 grams of each sample was heated at $105^{\circ} \mathrm{C}$ for 25 minutes 
and the weight lost as water was measured. Dividing by the sample weight $(10 \mathrm{~g})$, the wet-basis moisture content of pellets was given. For bulk density measurement, a standard one-litre container was used and weight of the pellets in the litre was measured. For pellet strength measurement, a three-point flexural bending test (bending to failure) was used to measure flexural stress of pellets $\left(\sigma_{f}\right)$ as given in Eq. 3. All the measurements were repeated 6 times to obtain an average value and standard deviation.

$$
\sigma_{f}(M P a)=\frac{F L}{\pi R^{3}}
$$

where $L(\mathrm{~mm})$ is support span (for current study, $20 \mathrm{~mm}$ was used for all tests), $F(\mathrm{~N})$ is the peak load force at the middle point on the pellet between the supports, and $R(\mathrm{~mm})$ is radius of the pellets.

\subsubsection{Dustiness test}

To determine abrasive attrition and dustiness of wood pellet, a rotary drum tester was used in accordance with EN 15210 standard [6]. The drum was $460 \mathrm{~mm}$ in length and $300 \mathrm{~mm}$ in diameter with 6 of $30 \mathrm{~mm}$ lift bars inside (shown in Figure 3).

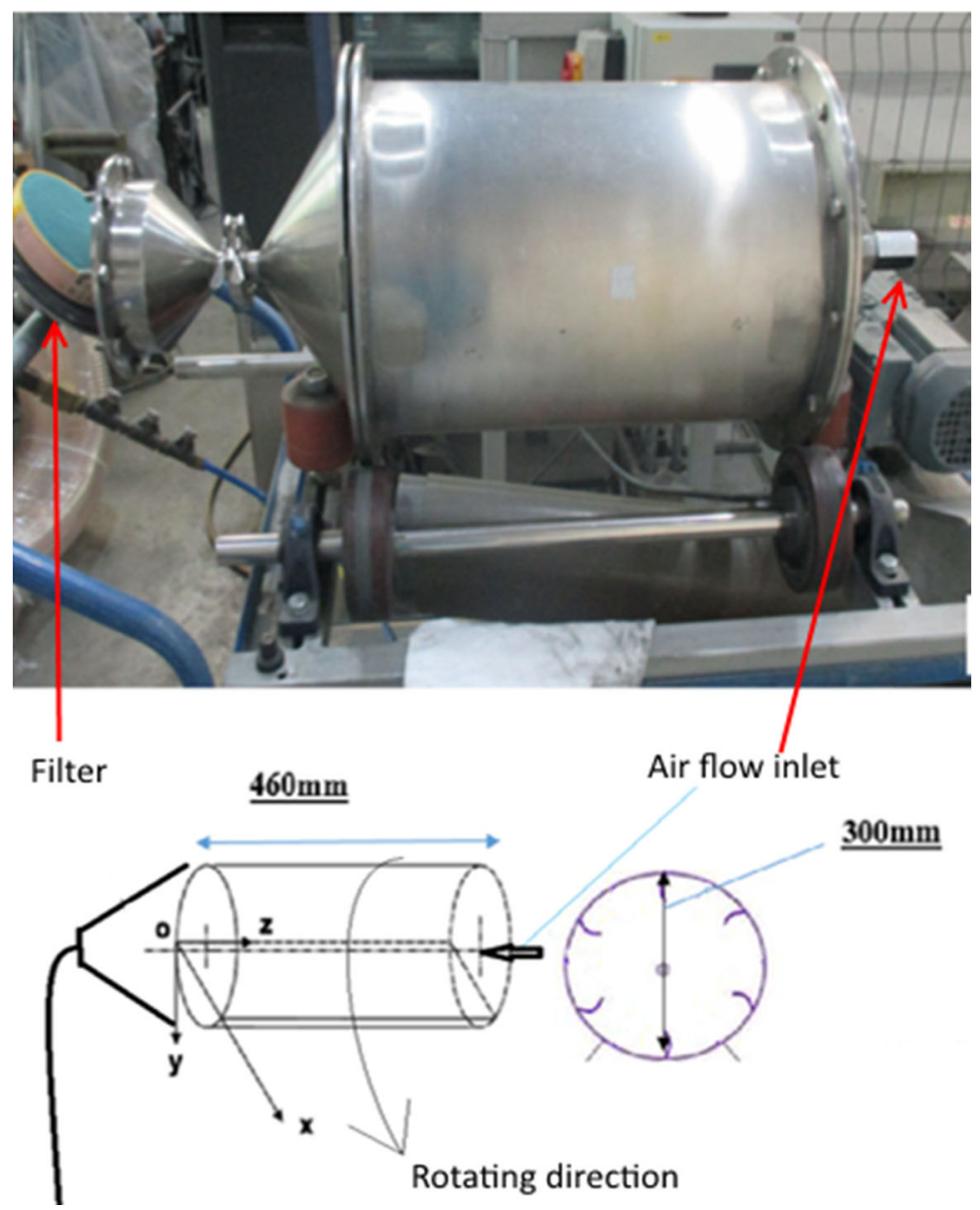

Figure 3: Rotating drum dustiness tester used at the Wolfson Centre

The drum was driven by a speed-controlled motor, running at $40 \mathrm{rpm}$ for a total of 500 revolutions (12.5 minutes). An airflow of $50 \mathrm{l} / \mathrm{min}$ was introduced through one end and ventilated via a filter foam pad that captured the dust in the air. The dust captured was weighed after tests and mechanical durability of the pellets in this test was calculated using Equation 1. Also size of the dust was analysed by a Malvern Mastersizer 2000. In the tests, a sample mass of 500 grams $\pm 1.0 \mathrm{~g}$ of unconditioned or conditioned pellets was used for a single test. The slightly higher air flow rate and superficial air 
velocity inside rotating drum $(0.012 \mathrm{~m} / \mathrm{s})$ was used $(50 \mathrm{l} / \mathrm{min}$ instead of $38 \mathrm{l} / \mathrm{min}$ specified in the standard) because a larger bulk sample size was applied.

\subsubsection{Impact attrition test}

A large scale centrifugal impact attrition tester previously developed at the Wolfson Centre [35, 36] for assessing breakage of large particles $(>1.0 \mathrm{~mm}$ ), was used for higher velocity impact tests involving more fragmentation. This consisted of a rotating disc ( $450 \mathrm{~mm}$ diameter) and set of equally spaced metal targets fitted onto a ring that surrounded the rotating disc (see Figure 4). The sample material was fed through a hole at the centre of the rotating disc by a feeding hopper. The sample particles were subsequently split evenly and then accelerated radially through eight radial channels by centrifugal forces. The particles were ejected from the channels with a final velocity consisting of a radial and a tangential component, and moved towards the targets. The pellets struck the targets at the designed impact velocity and impact angle. All the tested particles were collected carefully for size analysis and compared to the original particle size for breakage.

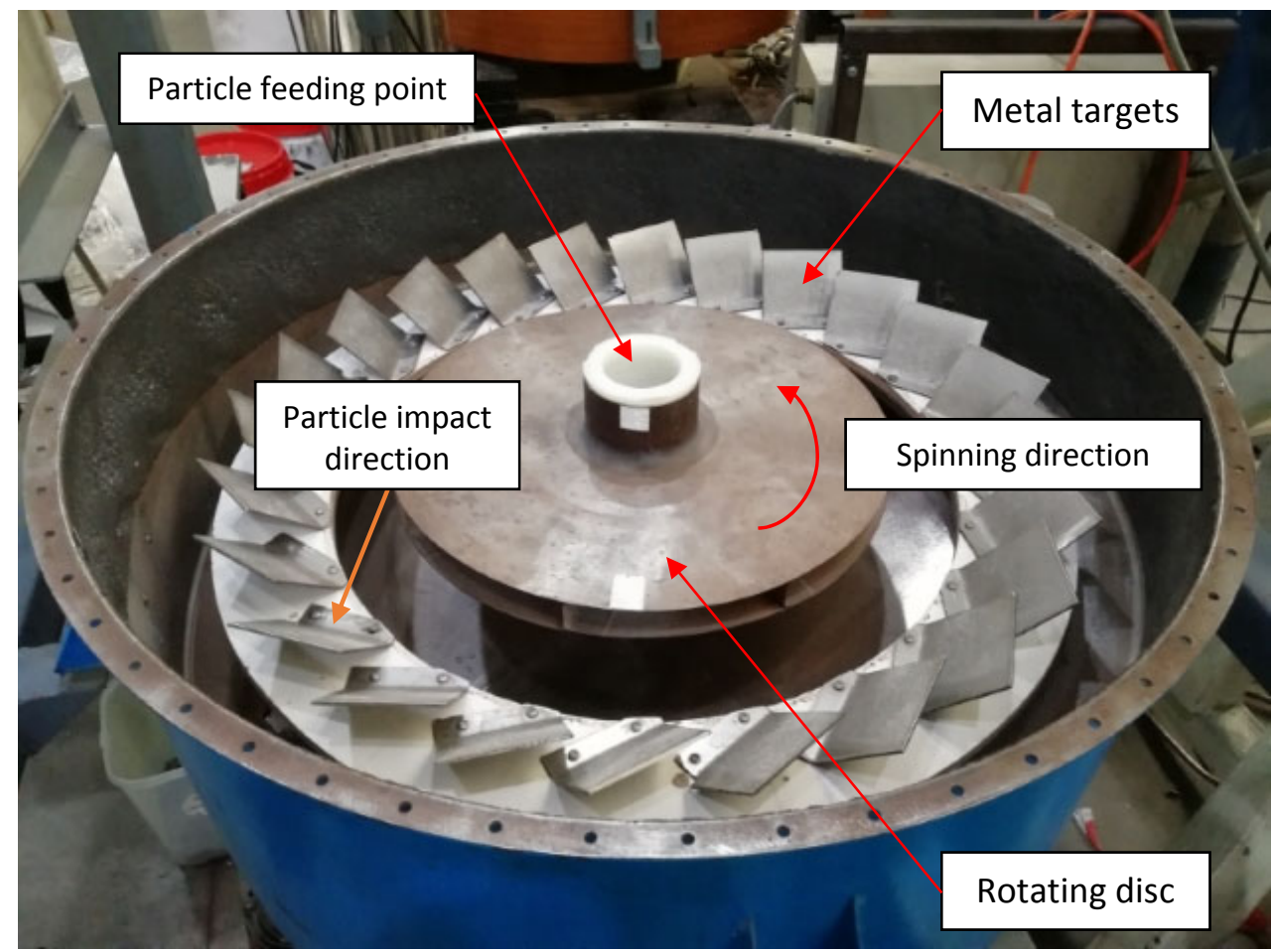

Figure 4: The large scale centrifugal impact attrition tester

The advantage of rotary impact testers is that they enable the determination of particle breakage under well controlled impact velocity and impact angles (by setting the angle of targets), which are the key factors influencing particle degradation under high speed impacts such as in a pneumatic conveying system. Also particle concentration, another influential parameter, can be well controlled by reducing particle feeding rate to the tester so any shielding effect can be avoided. This tester is able to rapidly generate the data by using a small amount of test samples for any size category required or a full size range.

In current tests, a 500 gram \pm 1.0 g sample of wood pellets was used for a single test and fed into the tester at a feeding rate of about $10 \mathrm{~g} / \mathrm{s}$. The disc rotated at a fixed speed of 578 revolutions per minute, which gave an impact velocity of $20.0 \mathrm{~m} / \mathrm{s}$. The targets were rotated at $45^{\circ}$ horizontally, which gave impact angle at $45^{\circ}$. A vibrator to the enclosure was used along with manual brushing to collect all samples. The collected sample was subsequently analysed by a $3.15 \mathrm{~mm}$ sieve and a vernier calliper. 


\subsection{Test conditions and sample conditioning}

A test programme was undertaken to study the influence of exposure to various humidities on the pellet attrition properties. Firstly the equilibrium relative humidity of the wood pellets was measured. Five humidity values were selected, which were $20 \%, 40 \%, 60 \%, 80 \%$ and $95 \% \mathrm{RH}$ at a constant temperature of $30^{\circ} \mathrm{C}$. These humidity levels were also used for studies of both physical properties and pellet attrition. These humidity values are typical of the range commonly indicated in public meteorology data for the Southern US states where large quantities of these pellets are manufactured, stored and loaded into ships.

For pellet attrition, degradation tests of wood pellets were carried out on both dustiness drum tester and rotary impact attrition tester so dust generation and pellet impact degradation can be assessed for the conditioned pellet samples. For conditioning of samples, the pellets were specially conditioned in a Climatic Test chamber (C340/40, Weiss Technik UK Limited) with humidity levels and the temperature for about 4 days. A typical conditioning diagram of pellet rate of weight change (percent change per hour) versus time is shown in Figure 5. An exponential decay curve fitted to this data indicates that the pellets would reach a stable moisture level after 24 hours (weight changes are less than $0.01 \%$ after this), so this gave confidence that the pellets would certainly be fully conditioned in 4 days. For any conditioned samples, the attrition tests were carried out immediately after the sample was taken out from the chamber so any further environmental influence was minimised. For pellet sizes, the collected test samples were analysed by mechanical sieves and the size ranges used were $<3.15 \mathrm{~mm}, 3.15-18.0 \mathrm{~mm}$, and $18.0-38.0 \mathrm{~mm}$. Except for the $3.15 \mathrm{~mm}$ sieve which was round hole, all others used were square mesh sieves.

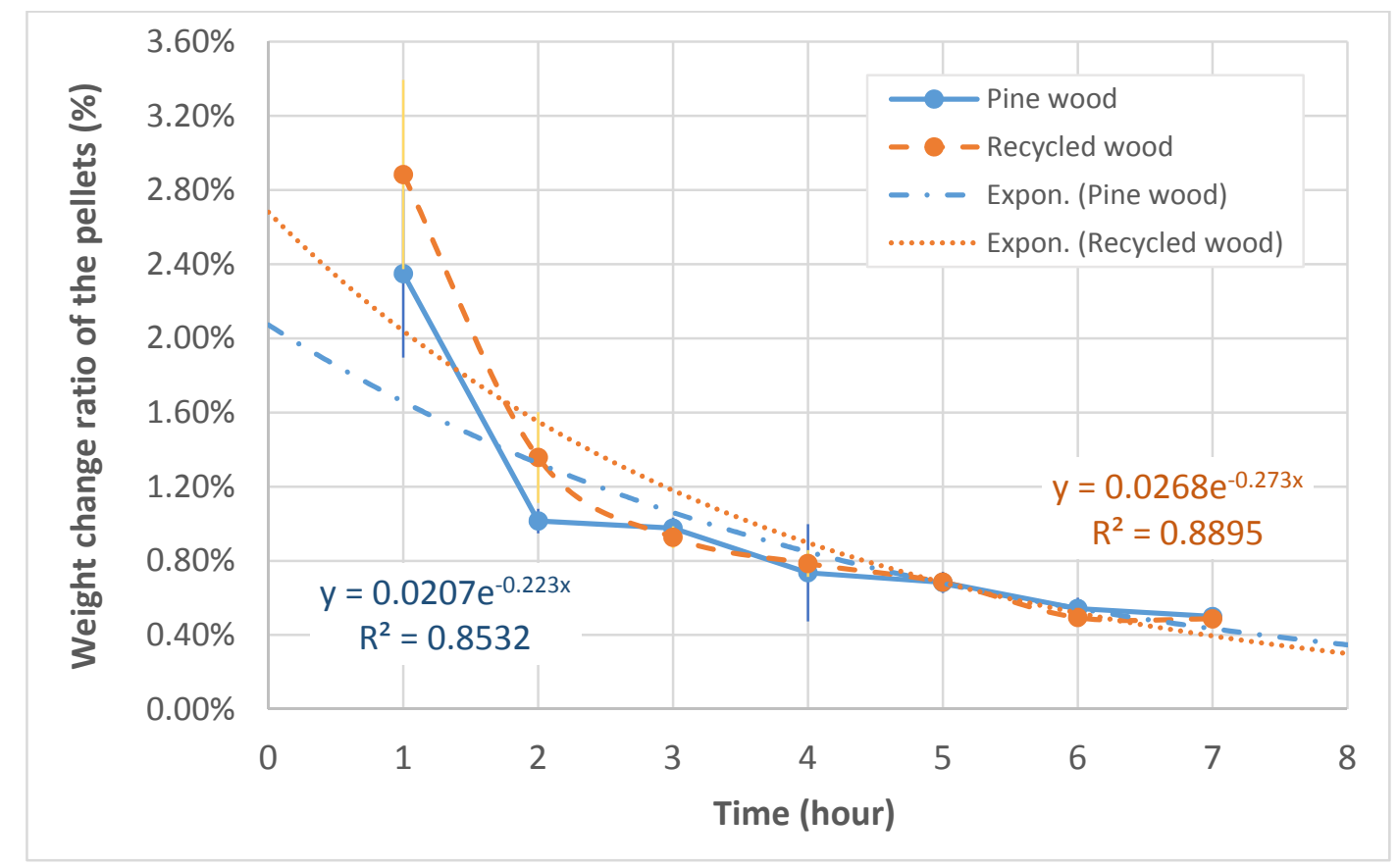

Figure 5: Example pellet weight changes (percent change in weight per hour) in an equilibrium condition of $95 \% \mathrm{RH}$ with fresh pellet samples, with exponential decay curves fitted

\section{Results and Discussion}

\subsection{Influences of humidity on pellets physical properties}

It has been reported that many physical properties of wood pellets may change due to humidity changes in storage environment, i.e., moisture contents and bulk density change, etc. [37]. Here, 
influence of humidity on physical properties of wood pellets has been studied in detail, which include moisture absorption, moisture contents, bulk density and mechanical strength.

\subsubsection{Moisture absorption of wood pellets}

In Figure 6, equilibrium moisture sorption curves of the pellets (measured using about 20 grams of pellets in a mono-layer on an open tray in the climate chamber) are given, which were measured at a constant temperature of $30^{\circ} \mathrm{C}$ degrees with $20 \%$ to $95 \%$ relative humidity $(\mathrm{RH})$ exposure for a 24 hours period for each humidity level continuously. After each period of time, the change of pellet weight was taken. The measurement started from increasing humidity first and decreasing humidity. With the results in Figure 5, it indicates that 24 hours are enough for pellet getting equilibrium. The absorption and desorption curves form a hysteresis loop; this is commonplace for organic materials and is believed to be due to the fact that energy is required to drive moisture into and out of the structure.

The samples were originally stored in a natural environment at around $46 \% \mathrm{RH}$ and already contained some moisture inside, which was $5.1 \%$ for the pine wood and $5.5 \%$ for the recycled wood pellets. The results showed that there was about $3 \%$ weight loss at $20 \% \mathrm{RH}$ due losing moisture, but a significantly increased mass above $80 \% \mathrm{RH}$ due to moisture gained. Between $40 \%$ and $60 \% \mathrm{RH}$, the moisture absorption and desorption were not significant.

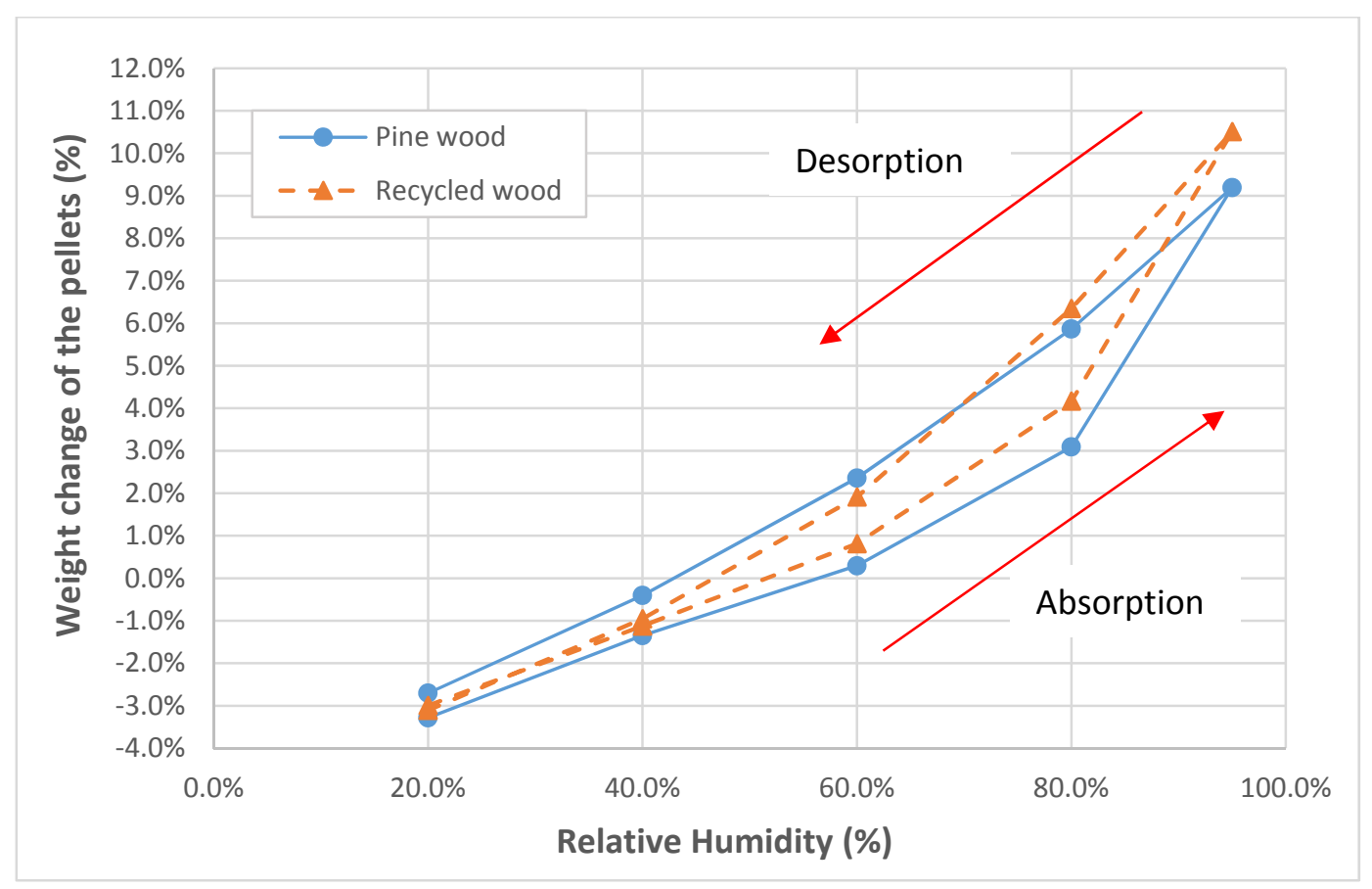

Figure 6: Equilibrium moisture sorption curves of the wood pellets with humidity exposure

\subsubsection{Influence of RH on moisture contents}

Moisture contents of the bulk-scale test samples of wood pellets after 4 days of conditioning were measured for the samples conditioned at different humidity levels $(20 \%-95 \% \mathrm{RH})$ in trays of approx. $1 \mathrm{~kg}$ in the climate chamber. Results are shown in Figure 7.

The results show an approximately linear increase of moisture contents in the pellets with increasing $\mathrm{RH}$, which is in agreement with previous study [38]. The ranges of humidity used in this study were informed by meteorological data covering the Southern US States in which large quantities of wood pellets are manufactured, stored, handled and loaded in large quantities [39]. For the both of samples, it shows a very similar trend of moisture contents according to humidity changes, where appears to have a major effect on the deterioration of pellets. With a humidity of $95 \% \mathrm{RH}$, the moisture was $14 \%$ 
for both samples. It means that the pellets can absorb significant moisture, if stored in an extreme humidity. This may influence the pellet strength and consequently pellets degradation behaviours.

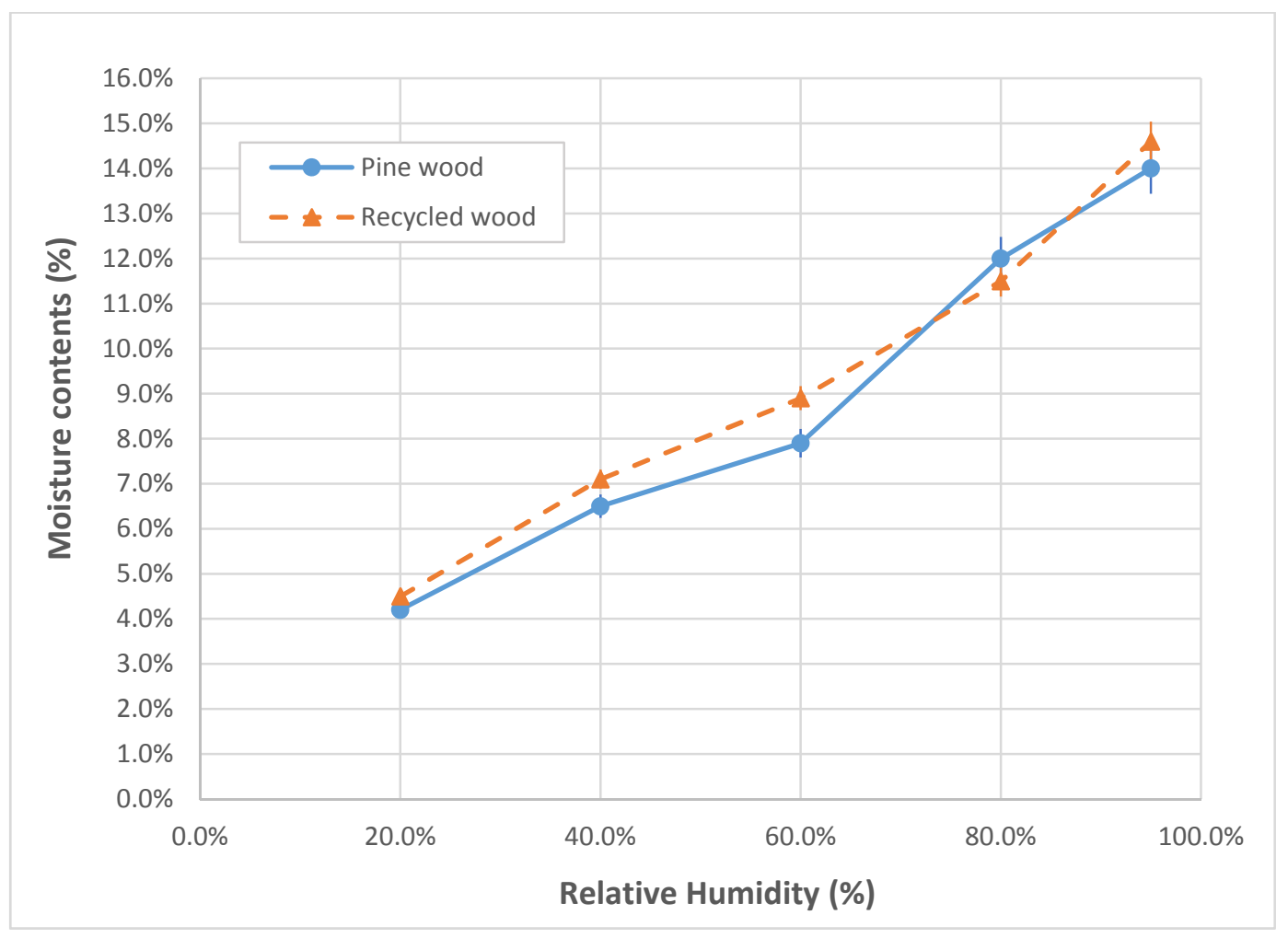

Figure 7: Measured moisture contents of the pellets conditioned at certain relative humidity levels

5.1.3 Influence of RH on bulk density and mechanical strength conditioning $\mathrm{RH}$, and results in Figure 9 give corresponding flexural stresses of the wood pellets.

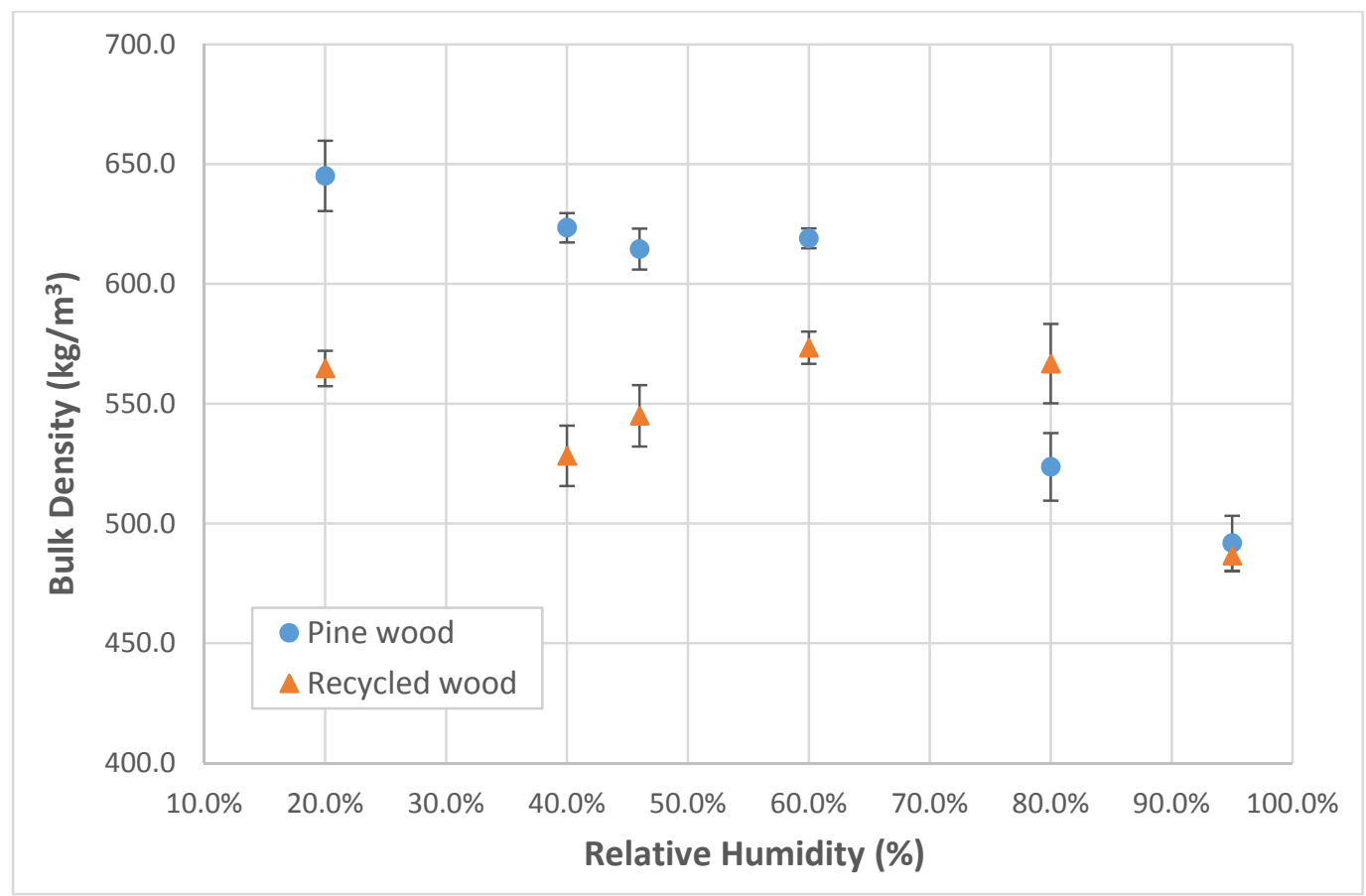

Figure 8: Bulk densities of the wood pellets at ambient and conditioned humidity RH based on 6 tests 
The results show that both bulk density and pellet flexural stress reduce with an increased relative humidity. In principle, if volume of the pellets does not change, bulk density of the pellets should increase when the pellets absorb water. However, decreased bulk density means that the pellets have expanded and the volume is increased when moisture content is increased. The results of pellet strength also confirm that the particles in the pellets must expand, which results in an increased volume of the pellets. This phenomenon seems to happen when the $\mathrm{RH}$ is greater than $60 \%$. In the experiments, appearance of the conditioned pellets seems not to change, except for at $95 \% \mathrm{RH}$. Comparing the pellets conditioned between $60 \% \mathrm{RH}$ and $80 \% \mathrm{RH}$, the average bulk density dropped about $10 \%$, but pine wood pellets dropped more significantly than the recycled wood pellets.

Similar results can be found for the pellet flexural stress, the pine wood pellets have the highest strength at $40 \%$ RH but the recycled wood pellets have the highest strength at $60 \% \mathrm{RH}$. For higher $\mathrm{RH}$, both pellet samples show the same trends for the bulk density and pellet strength.

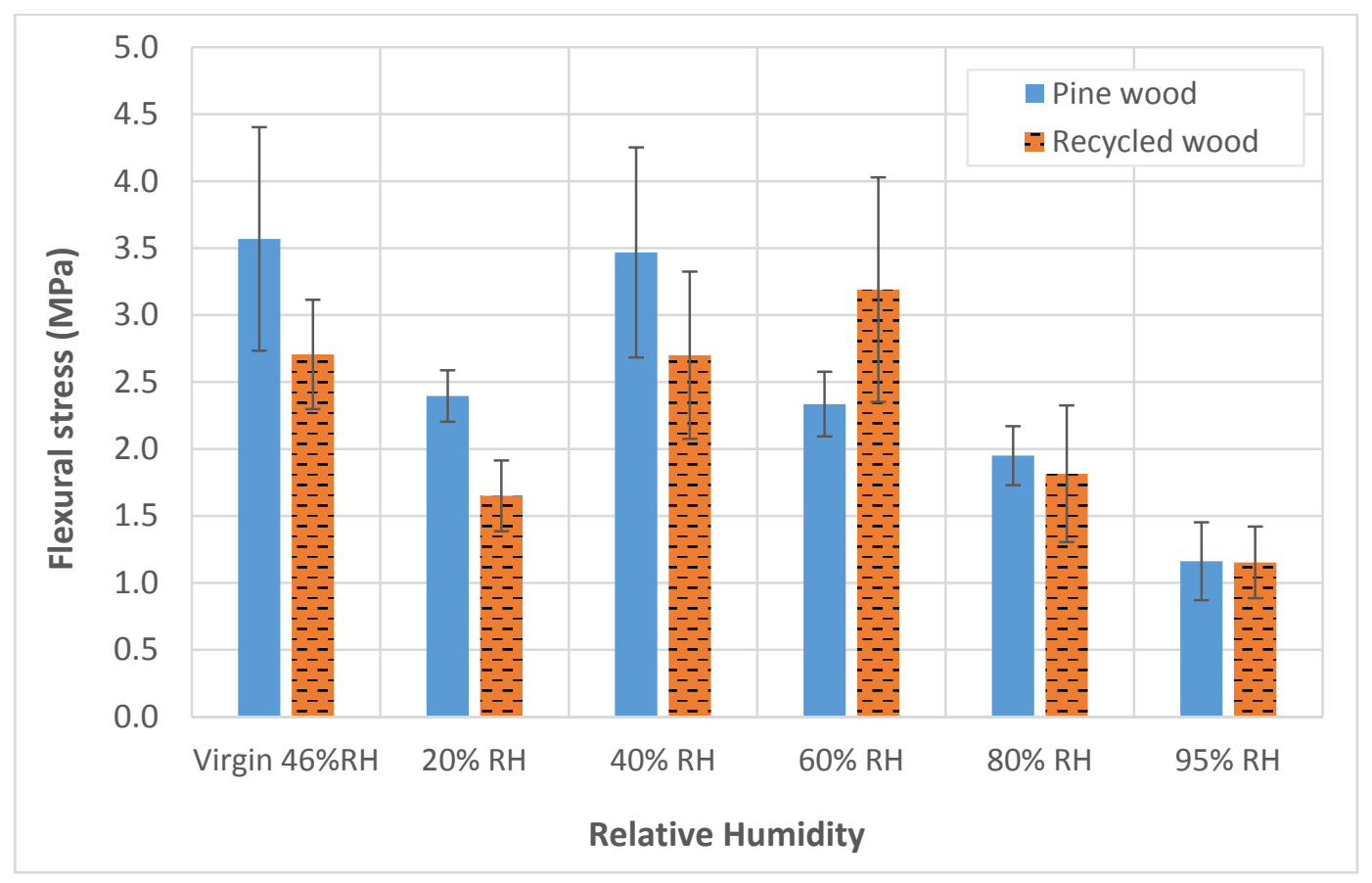

Figure 9: Flexural stresses of the wood pellets conditioned at different humidity RH based on 6 tests

\subsection{Influence of humidity on pellet attrition}

Because humidity influences the pellets mechanical properties such as moisture contents and pellet strength, humidity would be expected to influence attrition behaviour of the wood pellets. These have been studied on two types of attrition testers, impact attrition and dustiness tests for pellet durability.

\subsubsection{Impact attrition}

The impact attrition of the pellets have been tested at one impact velocity of $20 \mathrm{~m} / \mathrm{s}$ and one impact angle of $45^{\circ}$ degrees for a conditioned pellets sample of 500 grams. This has been done for one single test and the degradation results are shown in Figure 10, for unconditioned sample ( $46 \% \mathrm{RH})$ and conditioned samples at $20 \%, 40 \%, 60 \%, 80 \%$ and $95 \% \mathrm{RH}$. The following size categories were used for analysis: $<3.15 \mathrm{~mm} ; 3.15-18 \mathrm{~mm}$ and $18-38 \mathrm{~mm}$. The $-3.15 \mathrm{~mm}$ fraction was determined using a roundhole sieve $200 \mathrm{~mm}$ diameter and a shaker. Larger sizes were measured using a vernier calliper. The impact velocity of $20 \mathrm{~m} / \mathrm{s}$ was selected because it is close to a popular conveying velocity of wood pellets in pneumatic conveying systems. For the same reason, the impact angle of pellets in a short radius bend of pneumatic conveying systems is typically around $45^{\circ}$. 


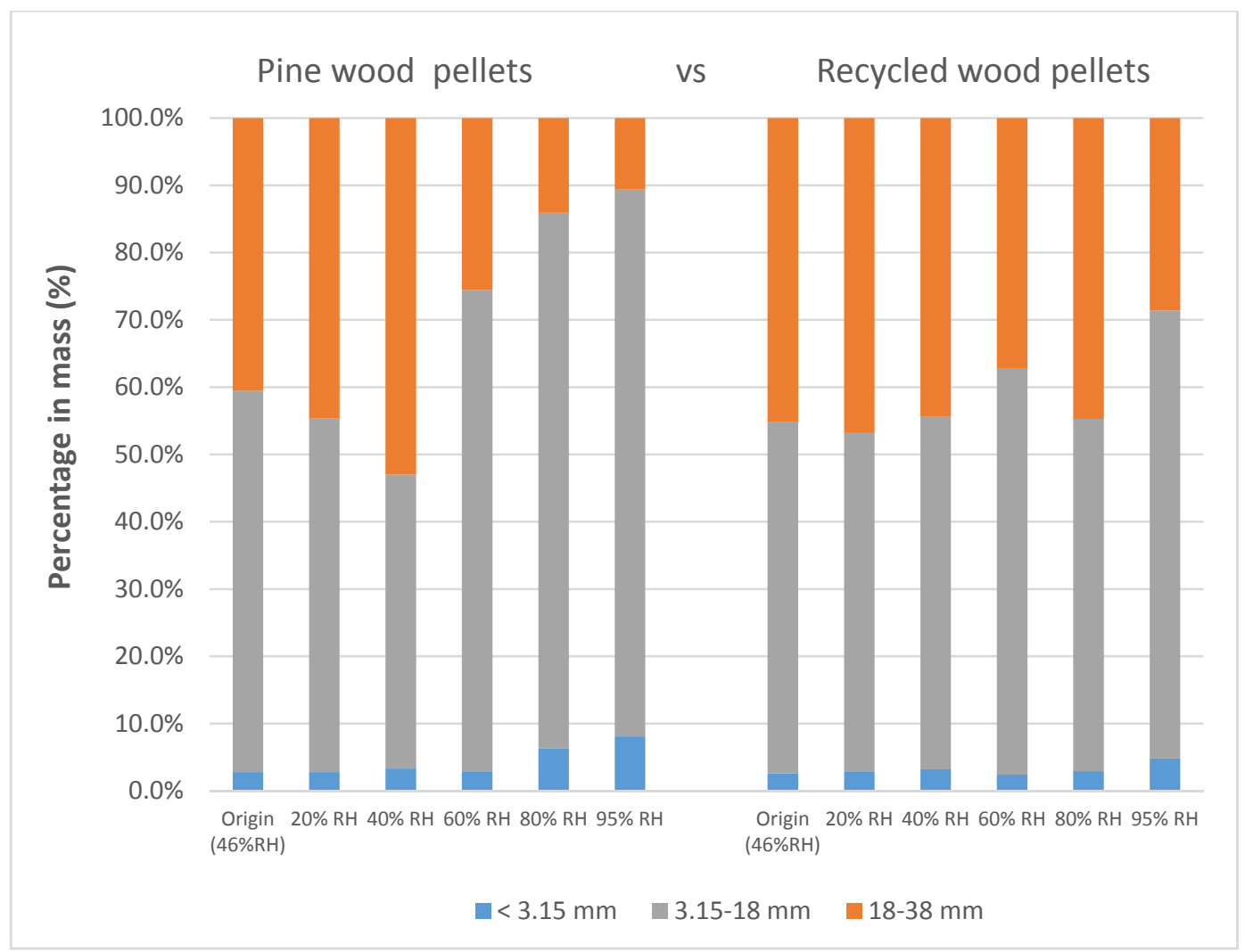

Figure 10: Size distributions of the pellets after $20 \mathrm{~m} / \mathrm{s}$ impact at $45^{\circ}$ impact angle

For virgin pellet samples, all the pellets were bigger than $3.15 \mathrm{~mm}$ in length before the impact tests and had a size distribution shown in Table 1. Therefore the results in Figure 10 are showing a size change after the impact tests at controlled impact conditions for the conditioned samples. In pellet utilisation, it is the fines content that causes combustion problems in some boilers, so the sub- $3.15 \mathrm{~mm}$ particle contents of the samples are shown on an enlarged abscissa in Figure 11.

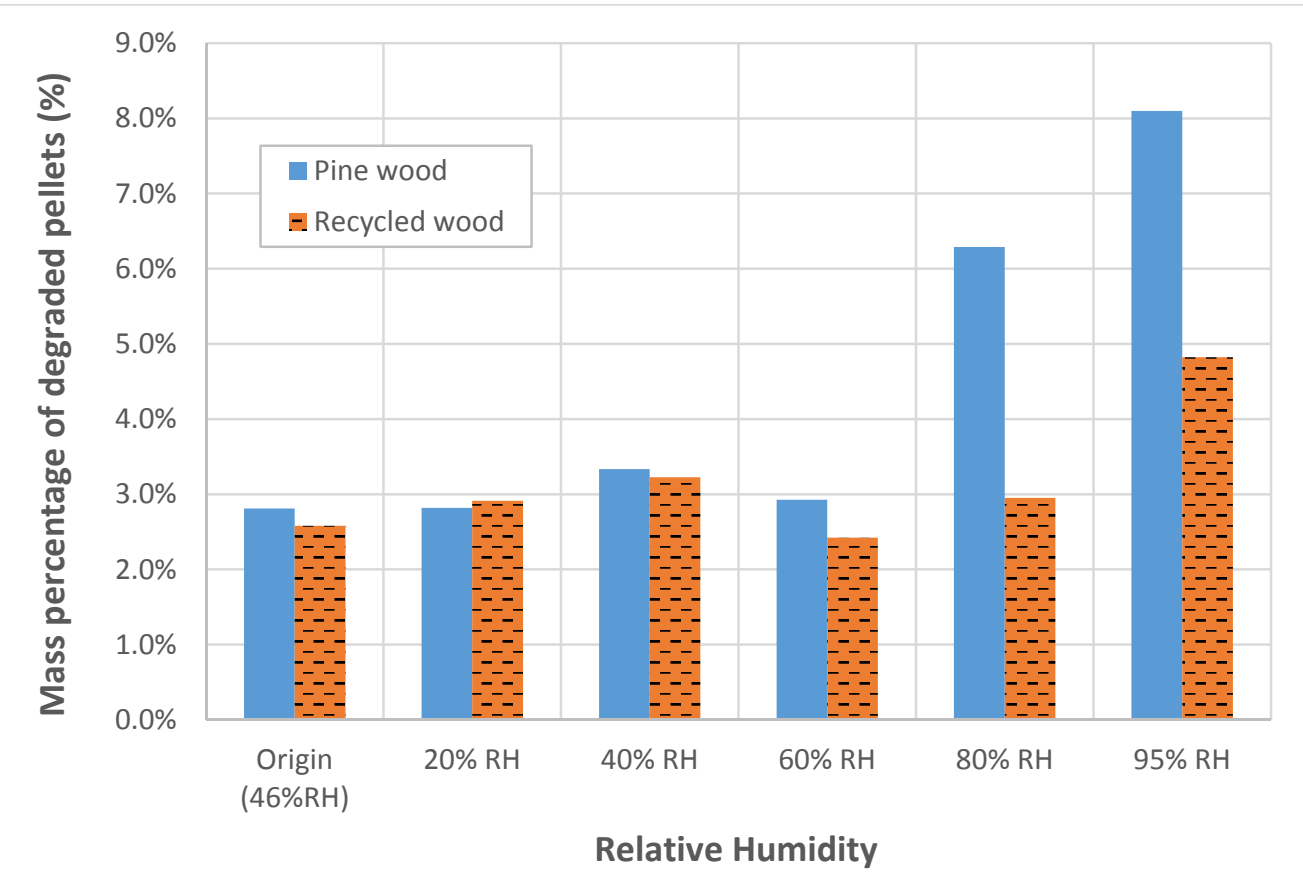

Figure 11: Degraded materials $(<3.15 \mathrm{~mm})$ after impacts at velocity of $20 \mathrm{~m} / \mathrm{s}$ and $45^{\circ}$ impact angle 
For the results shown, it can be seen that the pellets may break down more easily if exposed to a high humidity, i.e., $95 \% \mathrm{RH}$. For a normal ambient condition between $20 \% \mathrm{RH}$ and $60 \% \mathrm{RH}$, the pellets seem stable and levels of degradation are similar. The two different types of pellets had slightly different sensitivities to the humidity. The pine wood pellets showed a much higher degradation level at $80 \%$ $\mathrm{RH}$ in the tests, but the recycled wood pellets only showed substantial increase in attrition at $95 \% \mathrm{RH}$. For the both samples at $95 \% \mathrm{RH}$, the degradation was significantly increased and the number of long pellets dropped clearly.

For the pine wood pellets, a possible reason why they were more sensitive to the humidity may be because they had been stored in an ambient environment for almost three years, whereas the recycled wood pellets were recently purchased. Long term storage might possibly cause the pine wood pellets to be more susceptible to the effect of humidity due to aging effects of the wood pellets which have been shown to have some influence on strength and durability [24].

\subsubsection{Mechanical durability in tumbling test}

The dust generated during a simulated mechanical handling process with the conditioned wood pellets was measured by using the rotary drum tester described in section 4.3. The "durability" for the wood pellets is defined in Eq. 1. The results of dust generated (which is essentially equal to ' $100 \%$-durability') in tumbling tests are shown in Figure 12 for the samples conditioned at different humidity levels at $20 \%, 40 \%, 60 \%, 80 \%$ and $95 \% \mathrm{RH}$.

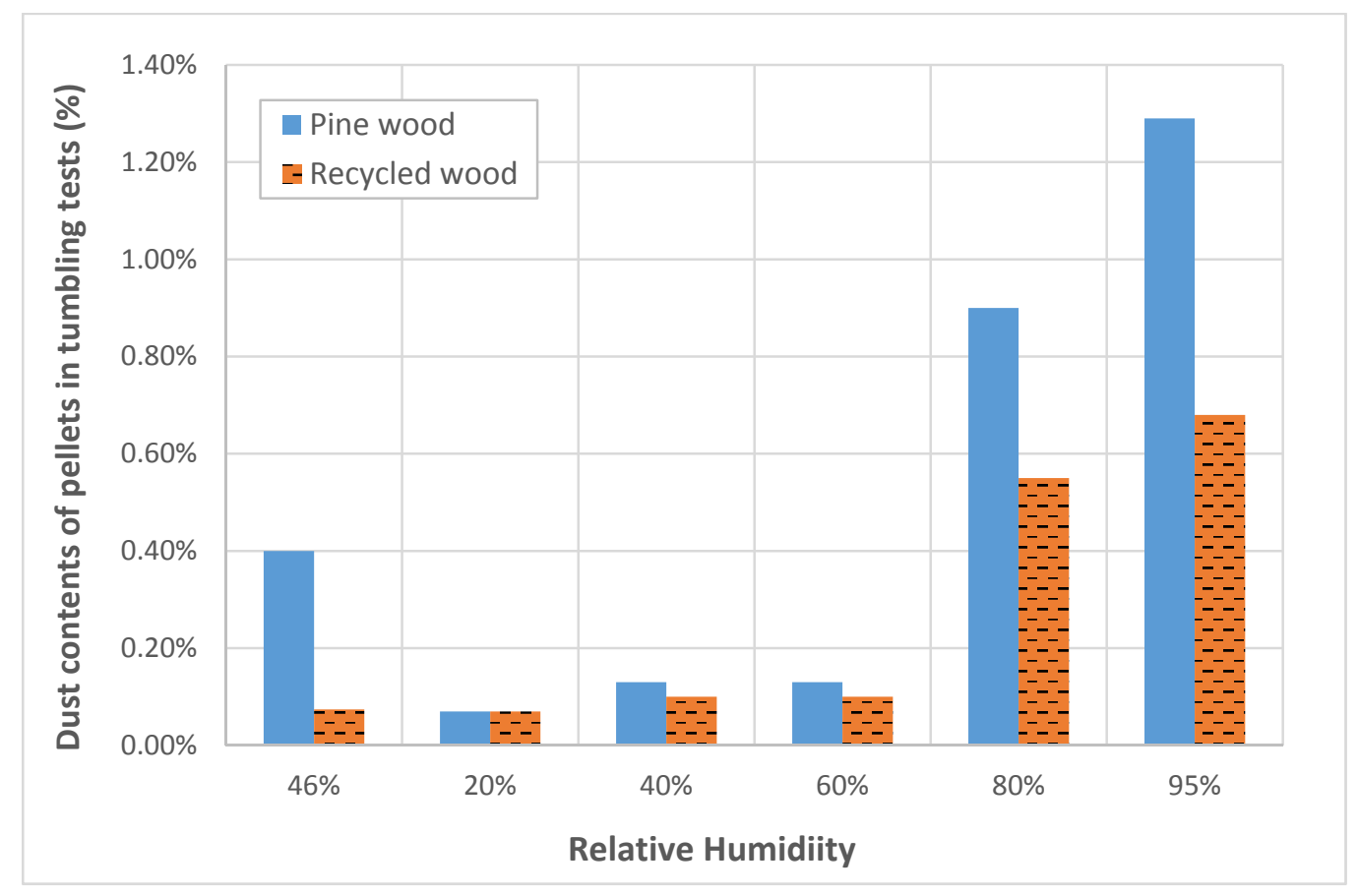

Figure 12: Dust contents of the conditioned (varied RH) wood pellets in tumbling dustiness tests (dust content is equal to ' $100 \%$ - pellet durability')

The results clearly show an increase of dust contents when humidity is higher than a certain level. Compared to the results in Figure 11, a broadly similar result can be found but in this test, both types of pellets showed very great increase in damage when conditioned at $80 \% \mathrm{RH}$ or above.

Comparing against the results in Figure 9 show that pellet flexural strength is also reduced with a high humidity level. This gives supporting evidence that the pellets can be weakened by high humidity, which results in the pellets being broken down more easily for the same impact energy so the pellets have less durability in handling. In the results, it is noticed that, for the $\mathrm{RH}$ between $20 \%$ and $60 \%$, the 
durability for both pellets has not changed much, so for an average or lower than average storage humidity, the wood pellets seem quite stable and the humidity has little effect on pellet degradation behaviour. But with higher humidity, the pellets may have permanent changes and become degraded more easily.

The size of dust particles generated in durability tests that were carried by the air flow $(50 \mathrm{l} / \mathrm{min})$ and collected by the filter was analysed (Figure 13) using a Malvern Mastersizer 2000. It shows that the top size of the dust is about $850 \mu \mathrm{m}$. Although the dust collected is only about $0.01 \%$ or less of the total sample weight, with an average particle size of $65 \mu \mathrm{m}$, the number of particles is huge and the particles are harmful as inhalable, which could cause severe problems in storage and handling of pellets especially in flat stores operated by mobile plant. This size distribution is also in the range that would be expected to lead to high values of explosion properties (rate of pressure rise and peak explosion pressure in a contained explosion) so the deposition of this dust in a working environment would present a high dust explosion risk.

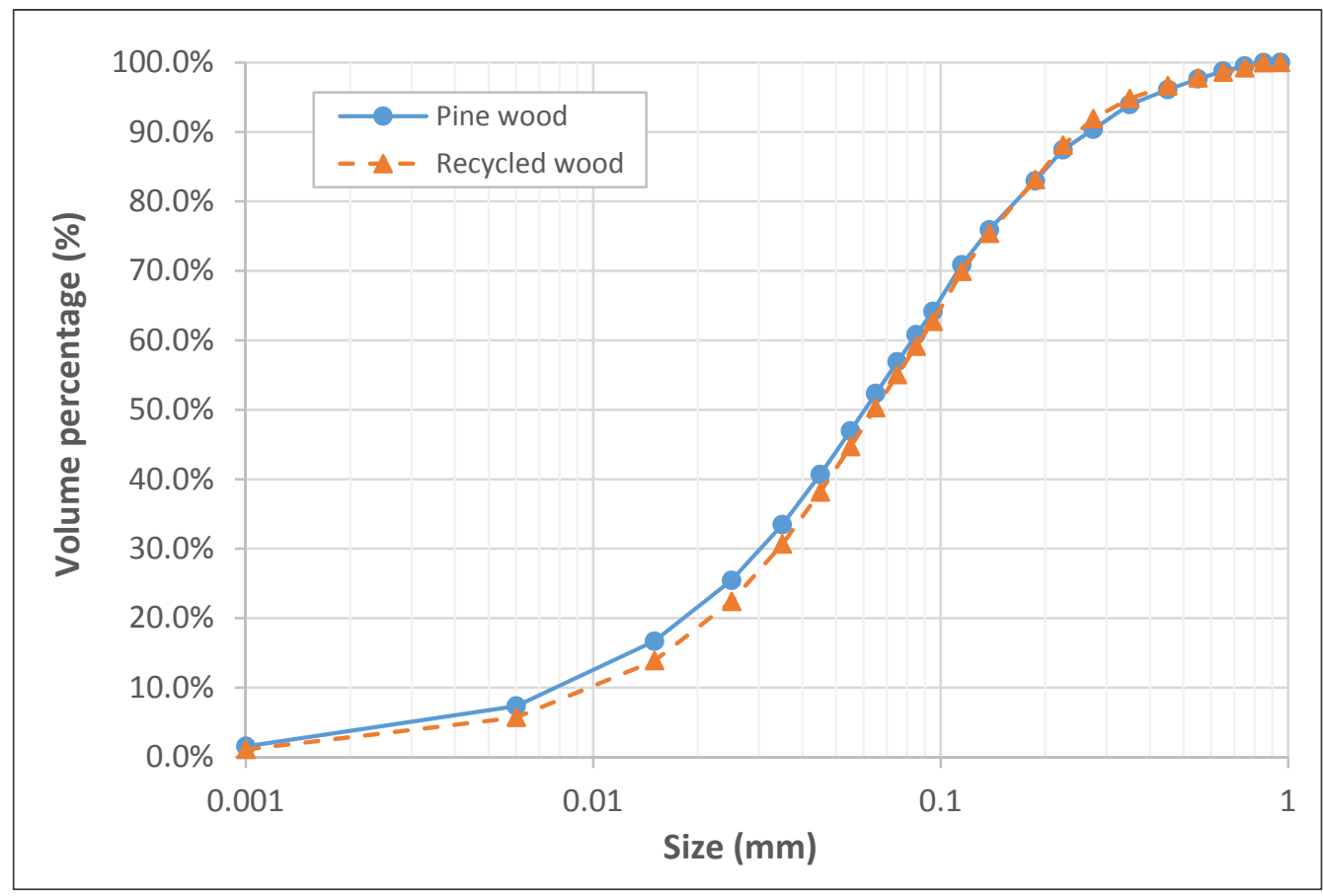

Figure 13: Size distributions of the dust collected by the filter in the rotary drum tester

\subsection{Discussion on humidity influences and pellets attrition}

As discussed, attrition of wood pellets can be due to fragments of small cells and whole pellets breaking down into smaller particles. Therefore the overall level of pellets degradation can be subject to two major factors: the number of total pellet particles involved and pellet mechanical strength if the same impact kinetic energy is applied.

The first factor is easy to understand, number of pellet particles. If degradation of single particles breaking into smaller particles is the same, more particles will produce more fine particles for the same impact energy applied. Therefore longer wood pellets broken down into more small particles would reasonably be expected to increase the level of fine particles. The results in Figure 10 show that for the pine wood pellets tested the percentage of longer pellets drops more than $50 \%$ at high humidity, while the levels of fines have significantly increased. For the recycled wood pellets, the results also show the same effect at $95 \% \mathrm{RH}$, with fines increase and coarse pellets decrease happening at the same time. 
For the second factor, pellet strength, this study shows some correlation between the pellet attrition and the pellet flexural stresses in Figure 14 and 15. In Figure 14, the results are for impact tests, which shows the level of fines $(<3.15 \mathrm{~mm})$ generated by $20 \mathrm{~m} / \mathrm{s}$ impacts at $45^{\circ}$ degrees. The results in Figure 15 show the dust release from the pellets with different levels of flexural stresses.

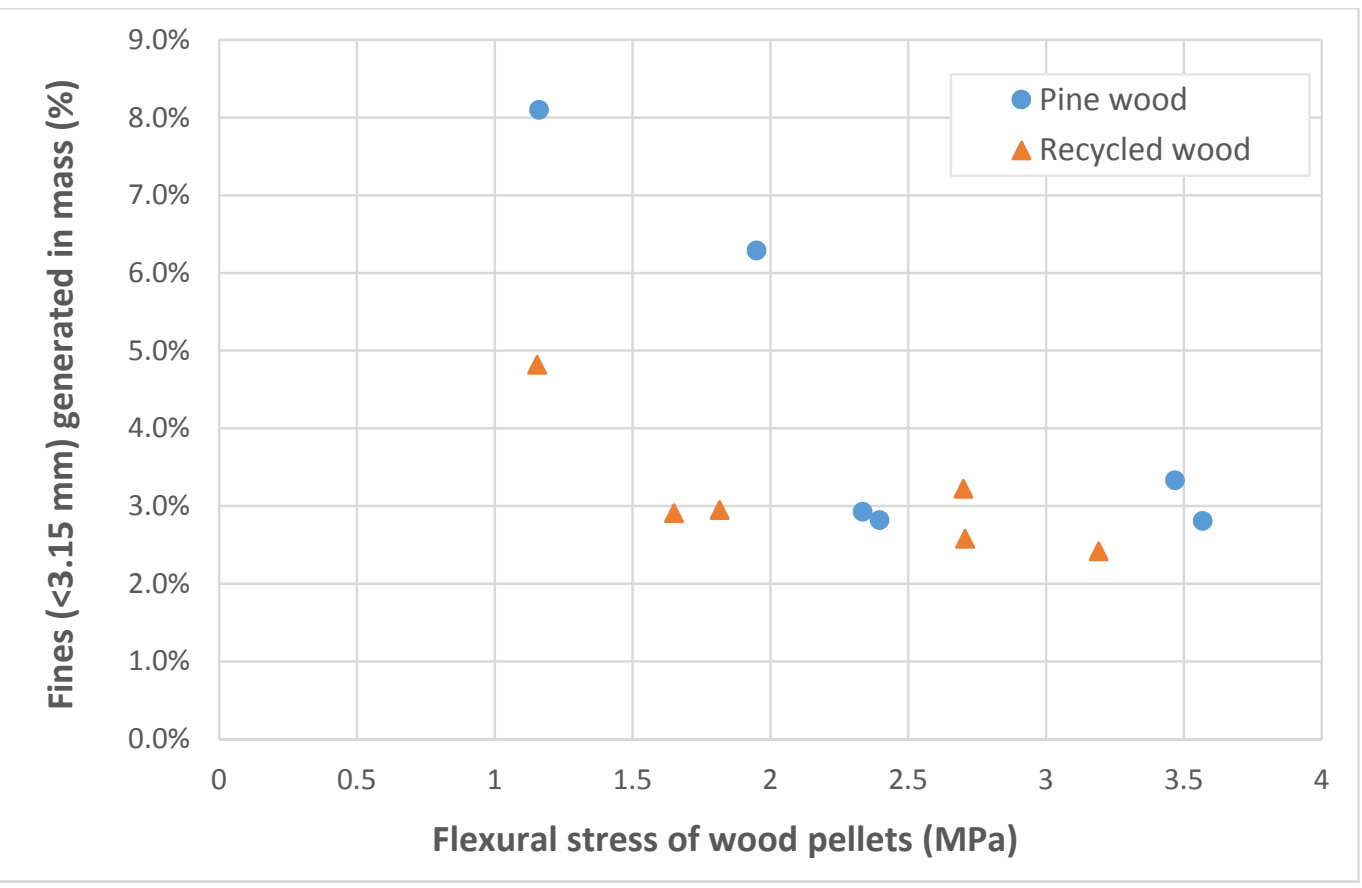

Figure 14: Level of fines $(<3.15 \mathrm{~mm})$ generated by $20 \mathrm{~m} / \mathrm{s}$ impact for the pellets with different

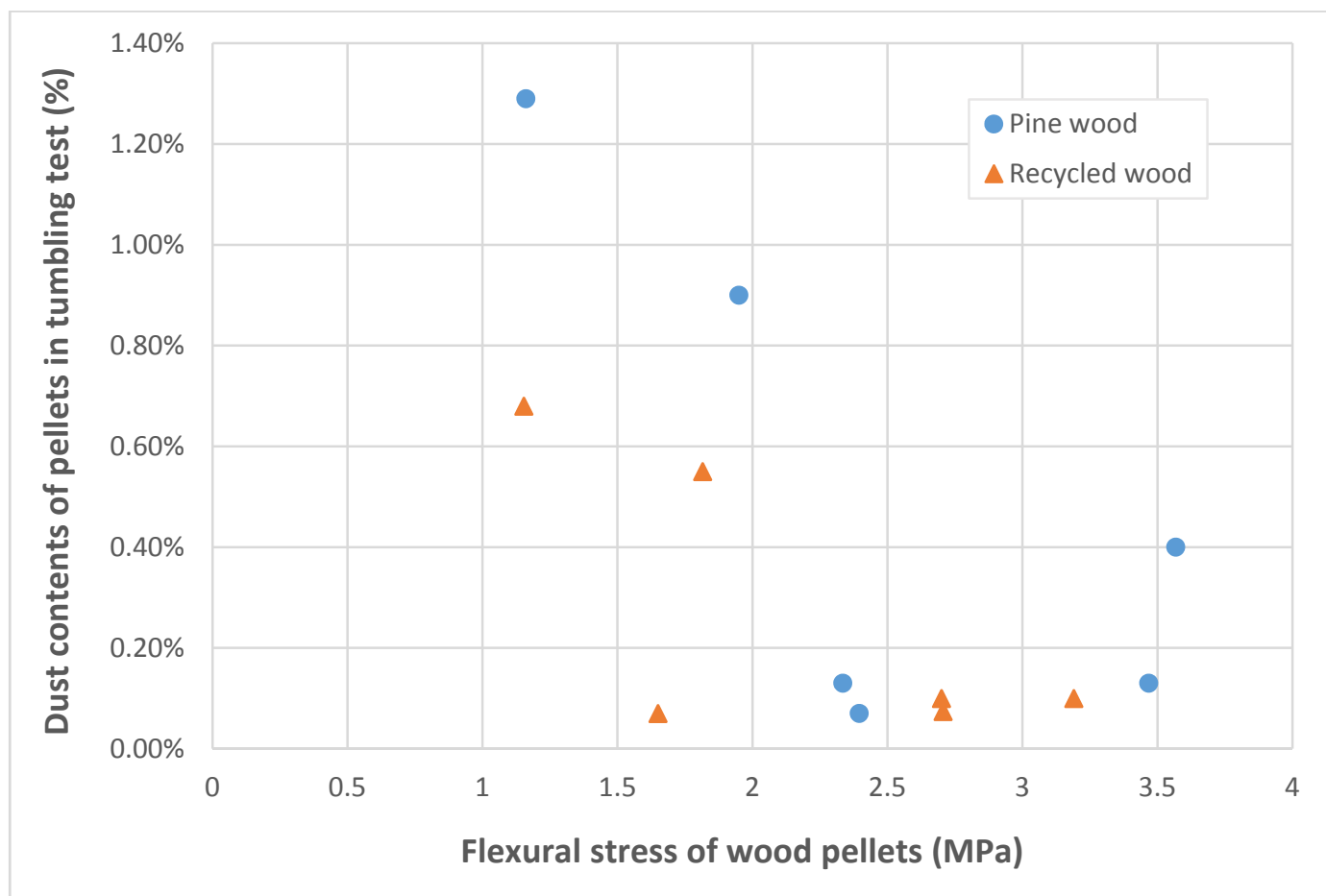

Figure 15: Dust contents (equal to '100\%-durability') of the conditioned (varied RH) wood pellets in tumbling dustiness tests with different levels of flexural stresses 
For the results in Figure 14, it can be seen that there is a clear trend that the fines content generated by the impacts had a similar level of about $2.5 \%$ to $3.5 \%$ over most of the range of flexural strength, but started increase when the pellet flexural stress is smaller than $1.6 \mathrm{MPa}$ for the recycled wood and 2.4 MPa for the pine wood. The level of fines generated was doubled to between $5.0 \%$ and $8.0 \%$ for the weaker pellets. The results show that there could be a critical point or "threshold level" of pellet strength, below which weaker pellets may generate more fines. Also the results show that the level of fines generated seems to be at a fairly constant level once the pellet strength reaches or exceeds the critical level.

The results in Figure 15 show a similar trend for the pellet dust contents in the tumbling drum, in which the pellets again have a similar dust level (other than one result) for the pellet strength bigger than about 1.6 MPa for the recycled wood and 2.4 MPa for the pine wood. Pellet strength of 2.0 MPa could be the critical point for the both. Generally, the pine wood pellets are weaker than the recycled wood pellets, possibly due to long storage time.

Dust weights collected by the filter in durability tests are shown in Figure 16. The results show a broad correlation, such that the dust weight released by the weaker pellets tends to be significantly higher than the stronger pellets. The results show a clear decreasing trend of dust release from the pine wood pellets when the pellet strength increases as shown in the figure. However for the recycled wood pellets, there trend to show increased dust when the pellets are weaker, is much less clear.

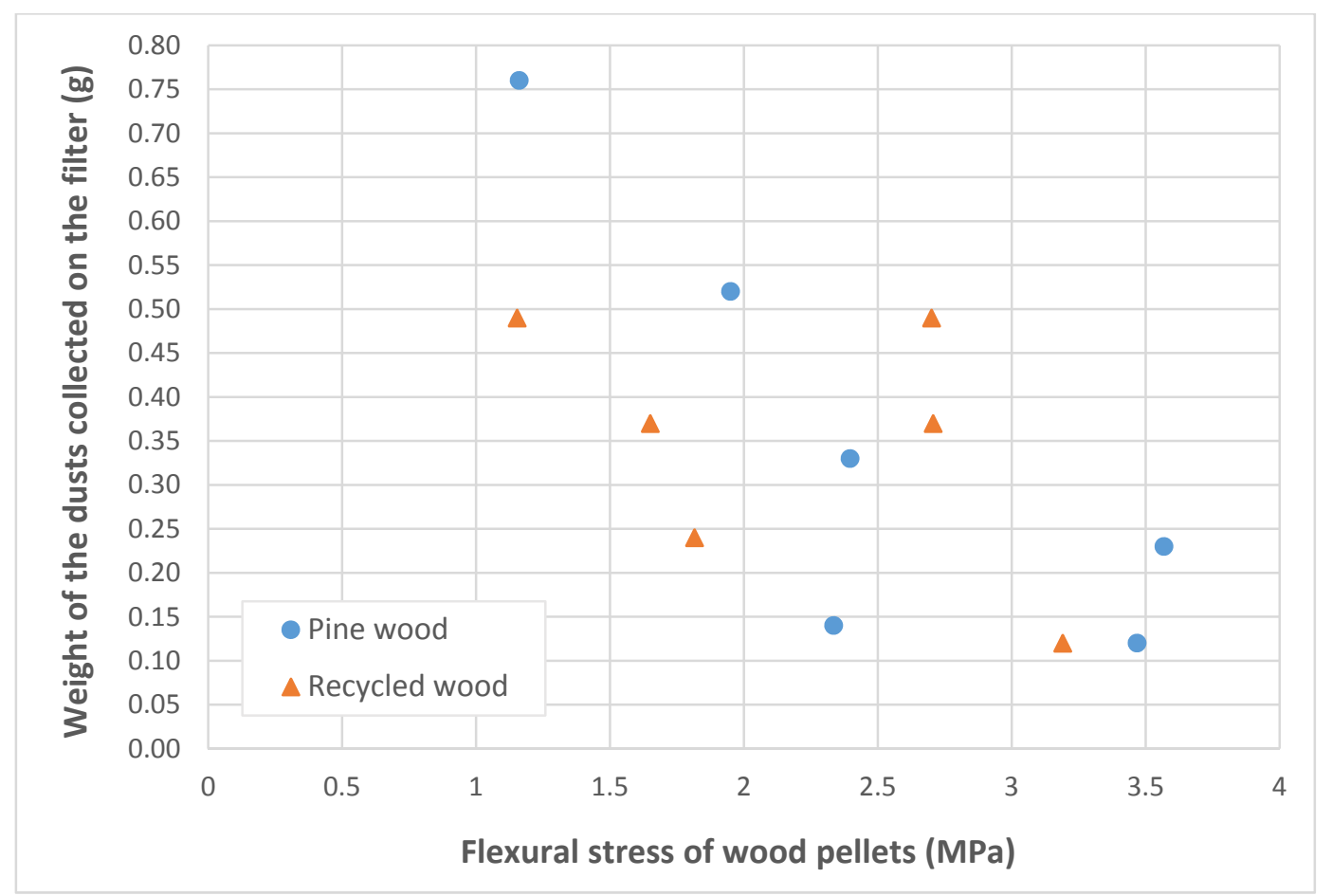

Figure 16: The weights of dusts collected by the filter for different levels of flexural stresses

The results in Figure 9 clearly show a tendency of the pellet flexural stress reduced with an increasing humidity level in storage. The photos in Figure 17 show the pellets that have been through humidity cycles of $20 \%-95 \%$ RH (shown in Figure 17 (a)) show more cracks on the surface and less smooth compared to the origin fresh wood pellets of the recycled wood pellets (shown in Figure 17 (b)).

Since humidity can influence pellet physical properties such as pellet strength by absorbing water, high humidity in storage environment definitely has influence on pellet attrition behaviour in handling processes. With occasionally high humidity while pellets are in store [39], the pellets may continue to 
lose strength in the period of a high humidity. Once in a transfer process, the pellets are more likely to suffer increased attrition and dust release, for example, impact damage at belt transfer points (around 3-10 m/s) or in pneumatic conveying systems (about $15-25 \mathrm{~m} / \mathrm{s}$ ) and abrasive damage in silos during off-loading.
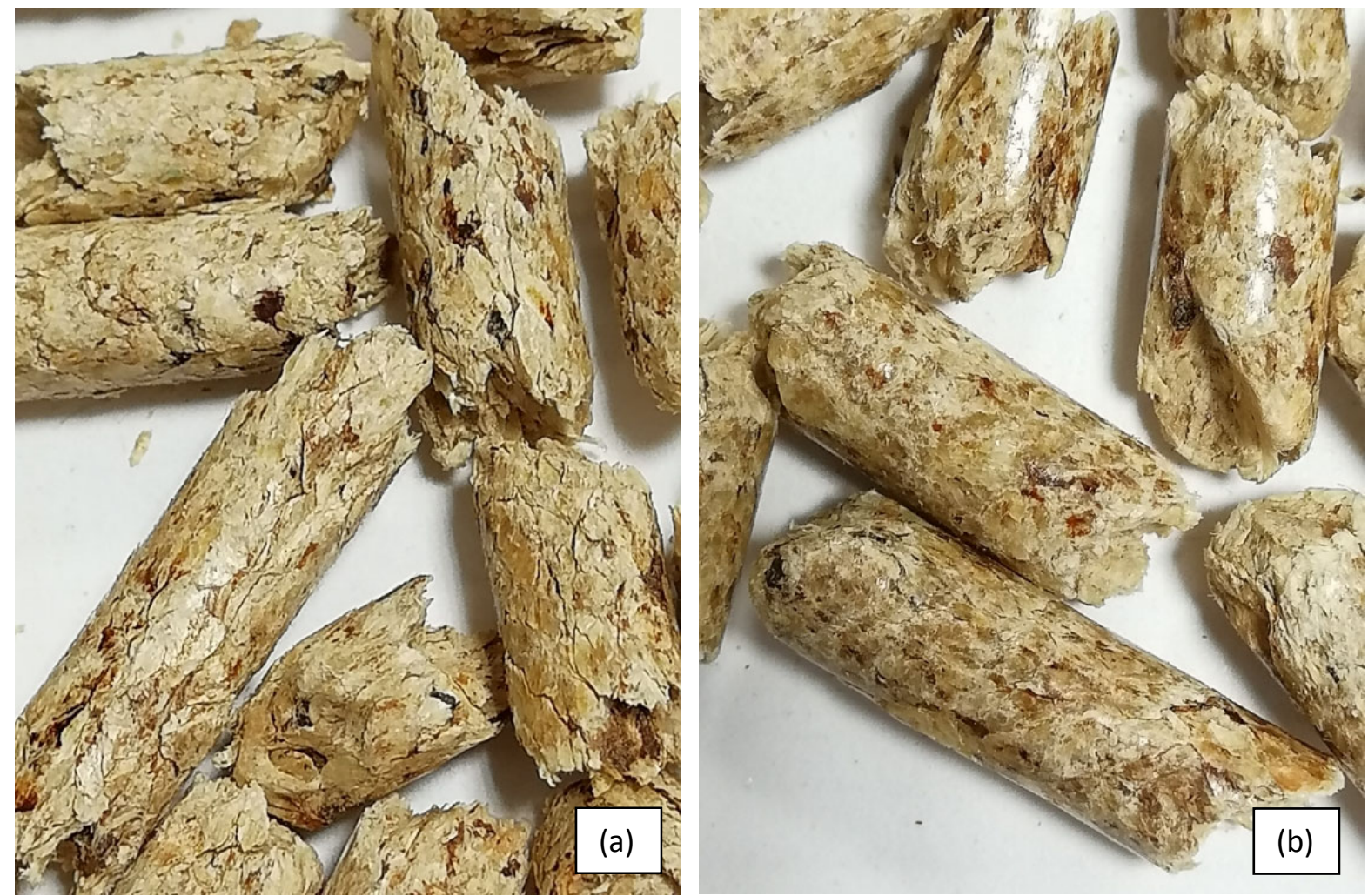

Figure 17: The samples of recycled wood pellets, (a) through humidity conditioned cycles, (b) fresh

For many cases, high humidity is difficult to avoid where the pellets are in storage or transportation, which will result in physical property changes of the pellets and consequently generate more pellet attrition in further handling processes. This study confirms that dust level can significantly increase once humidity reaches a high level such as more than $80 \% \mathrm{RH}$. Therefore preventing any high humidity levels in storage or controlling moisture contents in pellets can benefit further dust control and pellets attrition in material handling processes.

\section{Conclusions}

For this study, it is concluded that high environmental humidity can affect the physical properties of wood pellets significantly. Consequently with pellet property change such as pellet strength reduction, higher pellets attrition and more dust generated are expected.

In this research, it is found that pellets can absorb water in a high humidity environment which causes increases of moisture contents in pellets. However pellet strength does not proportionally decrease with the moisture content increase. Whereas the pellets will take up and lose water right across the humidity range, the results show that pellet flexural stress only starts to drop when humidity reaches a certain threshold level, typically $80 \% \mathrm{RH}$ or above.

Fragmentation and abrasion of pellets attrition behave similarly under the influences of environmental humidity. For different types of wood pellets, the threshold level is slightly different but the tendency of humidity influence once this threshold humidity has been exceeded, is broadly the same. Detailed conclusions can be summarised as follows: 
1. Wood pellets can absorb significant water and moisture contents may increase roughly proportionally, when the environmental humidity increases. This process appears to be fully reversible.

2. Bulk density and pellet flexural stress of wood pellets may reduce with a high relative humidity. However with a low humidity, i.e. below $70 \% \mathrm{RH}$, the bulk density and pellet strength do not have significant changes.

3. Wood pellets may break down easily once the pellets are exposed to a high humidity, i.e. $95 \%$ $\mathrm{RH}$. For a normal ambient condition between $20 \% \mathrm{RH}$ and $60 \% \mathrm{RH}$, wood pellets seem stable and levels of degradation are similar.

4. Two different types of pellets had slightly different sensitivities to humidity. The pine wood pellets showed a higher degradation level at $80 \% \mathrm{RH}$ in the tests, but the recycled wood pellets showed at $95 \% \mathrm{RH}$.

5. For pellet durability, similar results have been obtained and show a decrease tendency when humidity is higher than a certain level, for example $80 \% \mathrm{RH}$ or above.

6. The top size of the dusts collected during the durability tests is about $850 \mu \mathrm{m}$ with an average particle size D50 of $65 \mu \mathrm{m}$.

7. The level of fines generated was doubled for the weaker pellets, from $3 \%-4 \%$ to $5.0 \%-8.0 \%$. There appears to be a critical point on pellet strength, above which, the level of fines generated seems to be at a fairly constant level.

8. In regards to the above critical point concept, the pellets were found to have a similar durability level for strength bigger than about 1.6 MPa for the recycled wood and 2.4 MPa for the pine wood.

9. Dust weights collected show an increase when the pellet strength is reduced beyond a certain point for pine wood pellets, but not for the recycled wood pellets which have a similar level.

Overall, significantly increased damage and dust emission arising from high humidity exposure of wood pellets has been shown. The study indicates that preventing exposure to very high humidity will reduce pellet degradation and dust in the pellet handling process. It is clear, however, that the threshold level of humidity above which damage and dust emission will increase, is likely to be a function of the individual pellet type. This is probably the most important finding in terms of improving industrial practice; the authors recommend that the determination of this threshold humidity level for increased damage is an essential characterisation that should be undertaken for pellets from individual production streams, to allow the manufacturer and user to obtain an understanding of the importance and indeed the possibility of reducing pellet damage and dust emission in their facilities.

\section{Acknowledgement}

This research did not receive any grant from funding agencies in the public, commercial, or not-forprofit sectors, however the pine wood pellets were provided by Forever Fuels Ltd, Maidenhead, UK. The work was carried out by Mr Abdullah M. Alzahrani in his MSc study.

\section{References}

[1] Thrän D., Peetz D., Schaubach K., Global Wood Pellet Industry and Trade Study 2017, IEA Bioenergy, 2017, ISBN 978-1-910154-32-8

[2] Stelte W., Guideline: Storage and Handling of Wood Pellets, Resultat Kontrakt (RK) Report, 2012, Danish Technological Institute,

[3] Rohr, A.C., Campleman, S.L., Long, C.M., Peterson, M.K., Weatherstone, S., Quick, W. and Lewis, A., 2015, Potential occupational exposures and health risks associated with biomass-based 
power generation, International Journal of Environmental Research And Public Health, 12(7), pp.8542-8605,

[4] Koppejan J., etc., Health and Safety Aspects of Solid Biomass Storage, Transportation and Feeding, IEA Bioenergy, 2013,

[5] Labriet M., Biomass Production and Logistics, IEA-ETSAP, Technology Brief P09, 2013,

[6] BS EN 15210-1:2009, Solid biofuels. Determination of mechanical durability of pellets and briquettes, Part 1: Pellets, British Standard 2009,

[7] ISO 17831-1:2015, Solid biofuels -- Determination of mechanical durability of pellets and briquettes -- Part 1: Pellets, International Organization for Standardization 2015,

[8] Intelligent Energy Europe: Advancement of Pellets-related European Standards, WIP Renewable Energies, Munich, Germany, 2009

[9] Frew, I., Wypych, P. W. and Mar, L., (2013). Different modes of dust testing for bulk solids. ICBMH $2013-11^{\text {th }}$ International Conference on Bulk Materials Storage, Handling and Transportation (pp. 1-8). Australia: University of Newcastle

[10] Graham, S., Ogunfayo, I., Hall, M.R., Snape, C., Quick, W., Weatherstone, S. and Eastwick, C., 2016. Changes in mechanical properties of wood pellets during artificial degradation in a laboratory environment. Fuel Processing Technology, 148, pp.395-402.

[11] Graham, S., Eastwick, C., Snape, C. and Quick, W., 2017. Mechanical degradation of biomass wood pellets during long term stockpile storage. Fuel Processing Technology, 160, pp.143-151.

[12] Abdulmumini, M.M., Bradley, M.S.A.; Zigan, S., 2016. Prediction of wood pellets degradation in a pressurised tanker truck delivery system using bench scale testers, ICBMH $2016-12^{\text {th }}$ International Conference on Bulk Materials Storage, The Barton, ACT: Engineers Australia, 2016: 606-614. ISBN: 9781922107886

[13] Bradley, M., Effect of Fines Content on Pneumatic Conveying Properties of Wood Pellets, Report to Clyde Bergerman and Drax Power (2016), the Wolfson Centre for Bulk Solids Handling Technology, University of Greenwich, UK

[14] Whittaker, C. and Shield, I., 2017. Factors affecting wood, energy grass and straw pellet durability-A review. Renewable and Sustainable Energy Reviews, 71, pp.1-11.

[15] Döring S., Power from Pellets Technology and Applications, Springer, Berlin, Heidelberg, 2013, ISBN 978-3-642-19961-5

[16] Biswas, A.K., Rudolfsson, M., Broström, M. and Umeki, K., 2014. Effect of pelletizing conditions on combustion behaviour of single wood pellet. Applied Energy, 119, pp.79-84.

[17] European Pellet Council, Handbook for the Certification of Wood Pellets for Heating Purposes, 2013, European Pellet Council, Belgium

[18] BS EN ISO 17829:2015, Solid biofuels. Determination of length and diameter of pellets, British and International Organization for Standardization 2015.

[19] AS4156.6, Coal Preparation, Part 6: Determination of Dust/Moisture Relationship for Coal, Standards Australia, Sydney, 2000.

[20] Akdeniz R.C. and Esmer O., 2017, Effects of Length on Mechanical Durability of Various Wood Pellets, Hungarian Agricultural Engineering, N³2/2017 62-71, DOI: 10.17676/HAE.2017.32.62

[21] Tarasov, D., Shahi, C. and Leitch, M., 2013. Effect of additives on wood pellet physical and thermal characteristics: A review. ISRN Forestry, Volume 2013, Hindawi.

[22] Zamorano, M., Popov, V., Rodríguez, M.L. and García-Maraver, A., 2011. A comparative study of quality properties of pelletized agricultural and forestry lopping residues. Renewable energy, 36(11), pp.3133-3140.

[23] Samuelsson, R., Larsson, S.H., Thyrel, M. and Lestander, T.A., 2012. Moisture content and storage time influence the binding mechanisms in biofuel wood pellets. Applied energy, 99, pp.109-115. 
[24] Filbakk, T., Skjevrak, G., Høibø, O., Dibdiakova, J. and Jirjis, R., 2011. The influence of storage and drying methods for Scots pine raw material on mechanical pellet properties and production parameters. Fuel Processing Technology, 92(5), pp.871-878.

[25] Lee S.M., Ahn B.J., Choi D.H., Han G.S., Jeong H.S., Ahn S.H., Yang I., Effects of densification variables on the durability of wood pellets fabricated with Larix kaempferi $C$. and Liriodendron tulipifera L. sawdust, Biomass and Bioenergy, Volume 48, 2013, Pages 1-9.

[26] Stelte, W., Holm, J.K., Sanadi, A.R., Barsberg, S., Ahrenfeldt, J. and Henriksen, U.B., 2011. Fuel pellets from biomass: The importance of the pelletizing pressure and its dependency on the processing conditions. Fuel, 90(11), pp.3285-3290.

[27] Nielsen, N.P.K., Gardner, D.J., Poulsen, T. and Felby, C., 2009. Importance of temperature, moisture content, and species for the conversion process of wood residues into fuel pellets. Wood and Fibre Science, 41(4), pp.414-425.

[28] Carone, M.T., Pantaleo, A. and Pellerano, A., 2011. Influence of process parameters and biomass characteristics on the durability of pellets from the pruning residues of Olea europaea $L$. Biomass and Bioenergy, 35(1), pp.402-410.

[29] Kaliyan, N. and Morey, R.V., 2009. Factors affecting strength and durability of densified biomass products. Biomass and bioenergy, 33(3), pp.337-359.

[30] Wilson T.O., Factors affecting wood pellet durability, MSc thesis, The Pennsylvania State University. USA, 2010

[31] Oveisi-Fordiie E., Durability of wood pellets, MSc thesis, The University Of British Columbia, Canada, 2011

[32] Thomas, M., 1998. Physical quality of pelleted feed: a feed model study. ISBN 90-5485-872-9.

[33] ASAE S269.4 Dec 96, Cubes, pellets and crumbles-definitions and methods for determining density, durability and moisture content.

[34] Schott D.L., Tans, R., Dafnomilis, I., Hancock, V., \& Lodewijks, G. (2016). Assessing a durability test for wood pellets by discrete element simulation, FME Transactions, 44 (3), 279-284

[35] Wu, M. R., Schott, D. L., \& Lodewijks, G. (2011). Physical properties of solid biomass. Biomass and Bioenergy, 35(5), 2093-2105.

[36] Abdulmumini, M.M., Bradley, M.S.A. and Zigan, S., 2015. A comparative study of pelletizing process parameters on wood pellet durability. In Proceeding of the 8th International Conference for Conveying and Handling of Particulate Solids, Tel-Aviv, Israel.

[37] Lam, P.S. and Sokhansanj, S., 2014. Engineering properties of biomass. In Engineering and Science of Biomass Feedstock Production and Provision (pp. 17-35). Springer, New York, NY.

[38] Tumuluru, J.S., 2014. Effect of process variables on the density and durability of the pellets made from high moisture corn stover. Biosystems engineering, 119, pp.44-57.

[39] Annual Average Humidity in Florida, USA (where a large proportion of US produced wood pellets are loaded), https://www.currentresults.com/Weather/Florida/humidity-annual.php 